\title{
"Nanomaterials of curcumin-hyaluronic acid": their various methods of formulations, clinical and therapeutic applications, present gap, and future directions
}

\author{
Tanzeel Rehman Charan ${ }^{1 *}$ (D), Muhammad Aqeel Bhutto', Mihr Ali Bhutto', Azhar Ali Tunio1, \\ Ghulam Murtaza Khuhro', Sheeraz Ahmed Khaskheli ${ }^{1}$ and Ayaz Ali Mughal ${ }^{2}$
}

\begin{abstract}
Background: Nanomaterials of curcumin with hyaluronic acid have gained a lot of attention for potential therapeutic applications of curcumin and hyaluronic acid with or without other additional drugs. Overall studies of curcumin and hyaluronic acid show that nanomaterials of curcumin with hyaluronic acid accelerate the efficacy of curcumin in the treatment of various disorders like arthritis, cancer, hepatic fibrosis, neural disorders, wound healing, and skin regeneration, it is largely due to the combined effect of hyaluronic acid and curcumin. However, due to limited clinical trials and experiments on humans and animals, there is a substantial gap in research for the safety and efficacy of nanomaterials of curcumin-hyaluronic acid in the treatment of curcumin and hyaluronic acid targeted diseases and disorders.

Main body of the abstract: In this current review, we have first described various reported synthetic nanomaterials of curcumin-hyaluronic acid, then in the next section, we have described various fields, disorders, and diseases where these are being applied and in the final section of this review, we discussed the research gap, and future research directions needed to propose the fabricated nanocurcumin-hyaluronic acid biomaterials.

Short conclusion: There are substantial gaps in research for the safety and efficacy of nanomaterials of curcumin with hyaluronic acid due to limited available data of clinical trials and experiments of nanocurcumin-hyaluronic acid biomaterials on humans and animals. So, it entirely requires serious and committed efforts through the wellorganized system of practical and clinical trials which provide results, data, and detections that lead to the formulation of the best drug from curcumin with hyaluronic acid for the treatment of curcumin and hyaluronic acid targeted diseases and disorders.
\end{abstract}

Keywords: Curcumin, Hyaluronic acid, Nanomaterials, Biomolecules, Biotechnology

\footnotetext{
* Correspondence: trcharan@scholars.usindh.edu.pk

'Institute of Biotechnology and Genetic Engineering, University of Sindh, Jamshoro 76080, Pakistan

Full list of author information is available at the end of the article
}

\section{Springer Open}

(c) The Author(s). 2021 Open Access This article is licensed under a Creative Commons Attribution 4.0 International License, which permits use, sharing, adaptation, distribution and reproduction in any medium or format, as long as you give appropriate credit to the original author(s) and the source, provide a link to the Creative Commons licence, and indicate if changes were made. The images or other third party material in this article are included in the article's Creative Commons licence, unless indicated otherwise in a credit line to the material. If material is not included in the article's Creative Commons licence and your intended use is not permitted by statutory regulation or exceeds the permitted use, you will need to obtain permission directly from the copyright holder. To view a copy of this licence, visit http://creativecommons.org/licenses/by/4.0/. 


\section{Background}

For many centuries and decades, various medicinal plants have been used for the cure of different diseases and disorders. More than 400 medicinal plants have been used worldwide to reduce various risk factors associated with several diseases, like bitter melon (Momocardia charantia) for diabetes mellitus [1], garlic (Allium sativum) - a member of the Liliaceae family, which is one of the most popular herbs in the treatment of various diseases [2]. Among these all, medicinal plants, some plants, and their extracts possess versatile effects on the health of humans and other animals like curcumin the extract of turmeric (Curcuma longa L.). Nowadays, curcumin is counted among the most popular natural drug in the field of herbal medicines and pharmacology [3]. In recent years, various synthetic nanomaterials of curcumin with hyaluronic acid with or without some other additional compounds or drugs have gained a lot of attention in many fields of medicinal science and pharmacology, especially in the treatment of various disorders like arthritis, cancer, hepatic fibrosis, neural disorders, wound healing, and skin regeneration. It is largely due to the presence of medicinal plant extract curcumin, which possesses excellent anti-cancer, antitumor, anti-inflammation, neurotherapeutic, antibacterial, and antioxidant properties [4]. The available literature on nanomaterials of curcumin with hyaluronic acid suggests that, in these nanopolymer compounds, curcumin has always the position of the main compound or drug which plays the central role in the activities of nanomaterials of curcumin and hyaluronic acid and their various/different applications. In brief, curcumin is known to be turmeric plant extract, low molecular weight, and polyphenolic compound, which is an important bioactive ingredient found in the rhizomes of turmeric (Curcuma longa) [5].

The curcumin's IUPAC name is (1E,6E)-1,7-bis(4-hydroxy-methoxyphenyl)-1,6- heptadiene-3,5-dione. The chemical formula of curcumin is $\mathrm{C}_{21} \mathrm{H}_{20} \mathrm{O}_{6}$ and its molecular weight is $368.38 \mathrm{~g} / \mathrm{mol}$. The structure of curcumin consists of three chemical complexes: two aromatic o-methoxy phenolic groups, linked by a sevencarbon connector comprising a $\alpha, \beta$-unsaturated $\beta$-diketone moiety as in Fig. 1c [6].
Due to this chemical structure, curcumin has less aqueous solubility at acidic and neutral $\mathrm{pH}$, but it is soluble in ketone, alkali, ethanol, methanol, acetic acid, chloroform, and dimethyl sulfoxide (DMSO) [7]. Current research data of curcumin shows that it has ameliorative effects on the various human diseases, including cancer [8], lung and chronic kidney diseases [9, 10], diabetes [10], metabolic diseases [11], neurological disorders [12], liver problems [13], cardiovascular diseases [14], inflammatory diseases [15], and digestive disorders [16]. Even, curcumin also expresses control on particular molecular signaling pathways at the molecular level. Though, its effect on several targets in cellular pathways is suggesting it is a pleiotropic agent to control multiple actions [17]. Some important medical properties of curcumin are summarized in Fig. 2.

Despite various reported benefits of curcumin, its direct practical use is limited, due to its multiple factors and properties, for instance, curcumin has low solubility in water and physicochemical instability, poor bioactive absorption, poor bioavailability and pharmacokinetics, fast metabolization, weak targeting efficacy, and penetration, sensitivity to alkaline medium, heat, metals, ions, and light [18]. Therefore, these aforementioned limitations have been resolved by developing nanoformulations approaches like the fabrication of nanocurcumin biomaterial compounds [19]. Encapsulating curcumin into nanoformulation has been proved better methodology since the last decade, to overcome physiological barriers to increase efficacy and biological activities of curcumin in the body, this methodology helps in increasing solubility and bioavailability, retention and circulation of curcumin in the body, and increase physiochemical stability and pharmacokinetics [19-22]. So far, many researchers are using curcumin integrated into nanocarriers in nanoformulation-based approaches to developing better effects of curcumin in both in vitro and in vivo studies, like micelles, dendrimers, liposomes, conjugates, polymers, nanoparticles, and cyclodextrins [23, 24].

These nanoformulations of curcumin show their activities more effective when nanocurcumin is joined with natural hydrophilic polymer molecules. In this article,

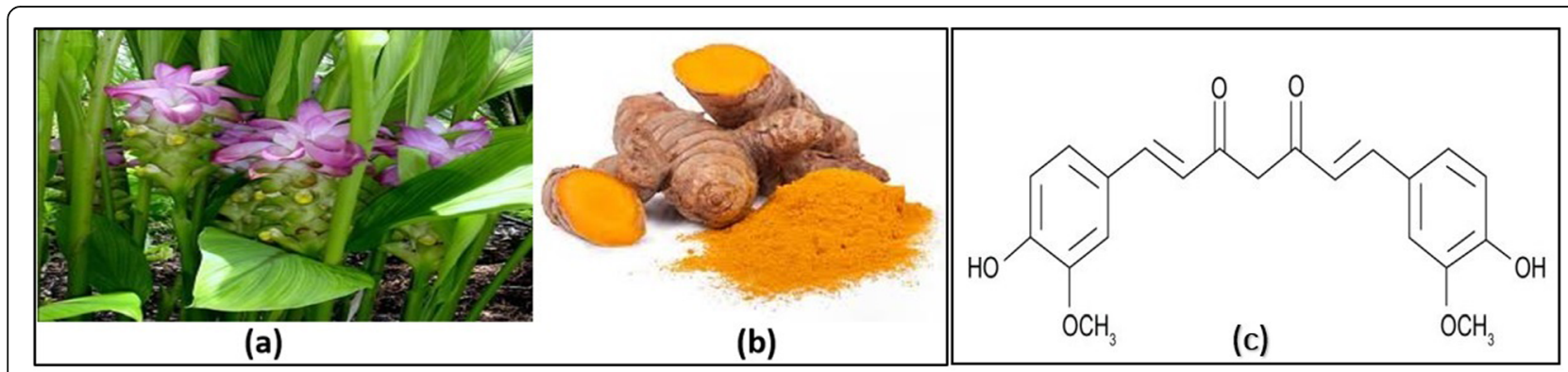

Fig. 1 a Curcuma longa, b rhizomes of turmeric and curcumin powder, $\mathbf{c}$ the chemical structure of curcumin 


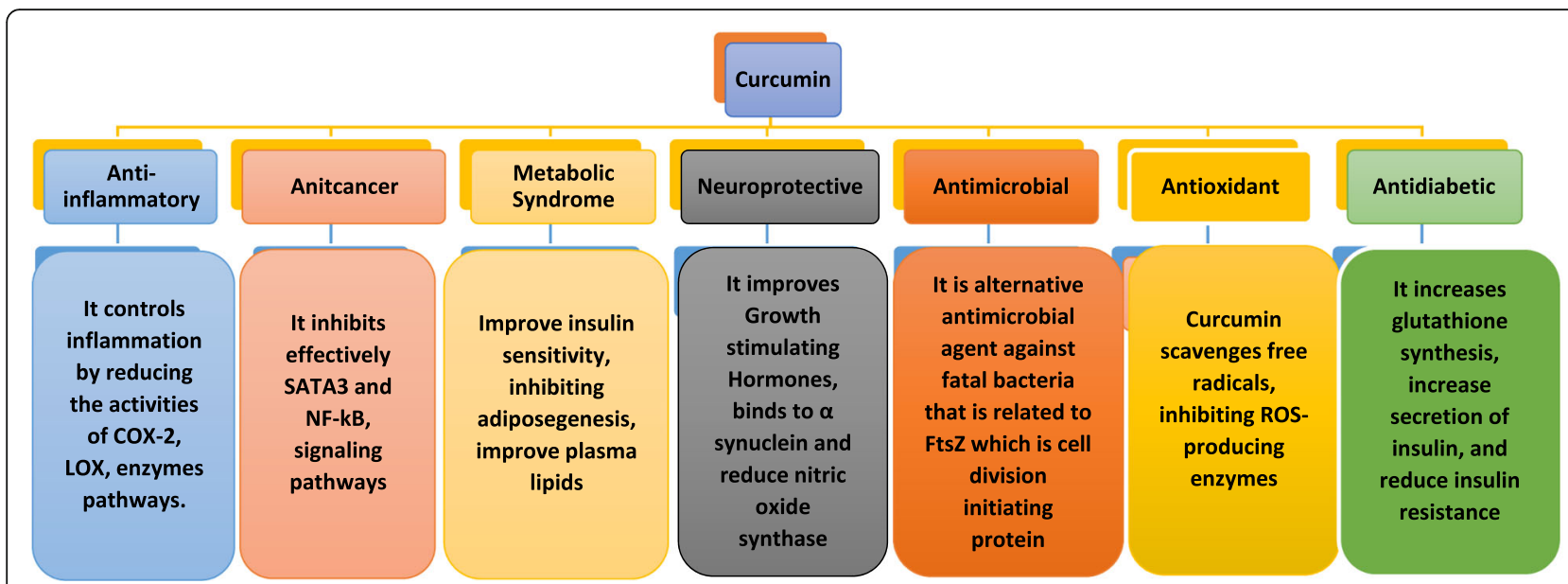

Fig. 2 Schematic diagram representing curcumin's some important medicinal properties: COX-2, cyclooxygenase-2; LOX, lipoxygenase; NF-kB, nuclear factor kB; SATA3, signal transducer and activator of transcription 3; $a$-Synuclein is a presynaptic neuronal protein that is linked genetically and neuropathologically to Parkinson's disease; FtsZ, filamenting temperature-sensitive mutant Z; ROS, reaction oxygen species

we focus on the various available nanoformulations and their clinical applications of nanocurcumin compound with hydrophilic polymers the hyaluronic acid, mainly due to nanoformulated curcumin-hyaluronic acid compounds are proving promising strategy for better drug solubility and to enhance drug stability of curcumin when tested practically in various fields $[3,25]$.

Hyaluronic acid (HA) is a natural polysaccharide, which contains D-glucuronic acid and N-acetyl-D-glucosamine. It has received a lot of attention in tissue regeneration applications [26]. It is naturally found in the extracellular matrix and possesses viscoelastic properties for bone joints in synovial fluid and also initiates cell proliferation where it is required in the body [27]. Further, being a hydrophilic polymer promotes hydration of skin [28]. It is worth mentioning that hyaluronic acid has its unique biocompatible, non-immunogenic, biodegradable, and non-allergic properties; therefore, it is being used for the synthesis of various advanced and promising biomedical therapeutic applications like nanoparticles [29], films [30], eye drops [31], nanofibers [32], dermal fillers [33], and non-adhesive bandage [34]. Hyaluronic acid powder, chemical structure, nanofibers with PVA, and eye drops of hyaluronic acid are presented in Fig. 3.
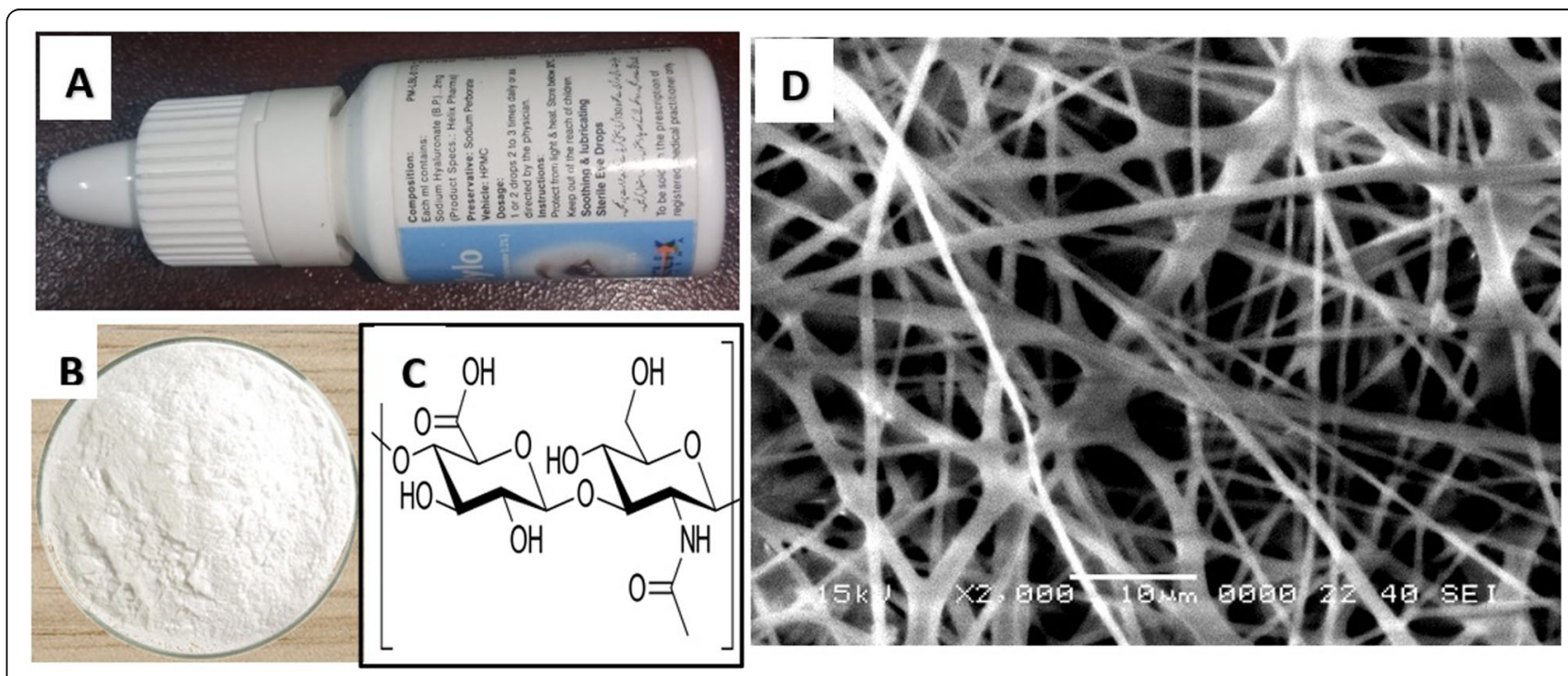

Fig. 3 (A) Eye drops of hyaluronic acid, (B) hyaluronic acid powder, (C) chemical structure of hyaluronic acid, (D) nanofibers of hyaluronic acid with PVA 
The current studies of hyaluronic acid suggest that nanomaterial of hyaluronic acid provides more advantages as compared with other polymers due to particular properties of hyaluronic acid like high sponge, specific surface area of fibrous structures, and higher permeability [35]. Figure 4 elaborates various therapeutic effects of hyaluronic acid particularly in osteoarthritis background.

Synthetic nanomaterials of curcumin-hyaluronic acid have been proved through various studies as the potential synthetic compound that augment the therapeutic efficacy of curcumin because curcumin alone cannot develop required results, due to its poor bioavailability, low solubility, rapid metabolism, and quick systemic elimination. Hence, nanomaterials of curcumin-hyaluronic acid are widely applying in different biological fields and their nanoformulation became possible due to advanced biotechnology and recent progress in synthetic methodology [28, 37]. Fabricated nanomaterials of curcuminhyaluronic acid and their applications have been extended clinical in vivo and in vitro studies. Since 2011, more than 100 publications related to curcuminhyaluronic acid nanoparticles are available in the NCBI PubMed database (hyaluronic acid curcumin - Search Results - PubMed, 2020-11-12) [38]. Earlier, many researchers worked on the improvement of the bioavailability of curcumin, but later worked on the combined effect of curcumin and hyaluronic acid targeted diseased areas. Nanomaterials of curcumin-hyaluronic acid were encapsulated into various forms like nanomicelles, liposomes, nanogels, gold nanoparticles, pullulan, and cyclodextrin. Throughout all online available paper studies, it is clear that the fabricated nanomaterials of curcuminhyaluronic acid, accelerate the efficacy of curcumin in their selected targeted areas like the healing of wound and reduce scar formation [28], treat rheumatoid arthritis [37], treat various cancers more effectively [39].

In this current review, we first describe variously reported nanomaterials of curcumin-hyaluronic acid. In the next section, we describe the various fields, disorders, and diseases where these are being applied. In the last section of this review, we elaborate on the present research gap, and future research directions required to propose nanocurcumin-hyaluronic acid biochemical compounds.

\section{Methods for nanoformulation of nanomaterials of curcumin with hyaluronic acid}

There are various forms, methods, and applications of nanoformulation of curcumin, reported in researches, like micelles, liposomes, polymers, gold nanoparticles, magnetic nanoparticles, solid lipid nanoparticles, conjugates, cyclodextrins, solid dispersions, nanospheres, nanogels, and nanodisks, but the known fabricated nanocurcumin-hyaluronic acid biomaterials are limited on certain forms; the list of forms is given in Table 1.

\section{Micelle}

A micelle or micella is referred to as an aggregate of amphiphilic surfactant molecules that spontaneously dispersed in water producing colloidal suspension [53]. Almost all kinds of micelles in the field of biotechnology are used to deliver specific poor water-soluble drugs to targeted regions thus function as taxi cabs. Previous studies show it has been successfully used for delivering curcumin to the targeted cells [54].

Likely, Fan et al. constructed a curcumin-hyaluronic acid (Cur-HA) nanomicelle, which developed

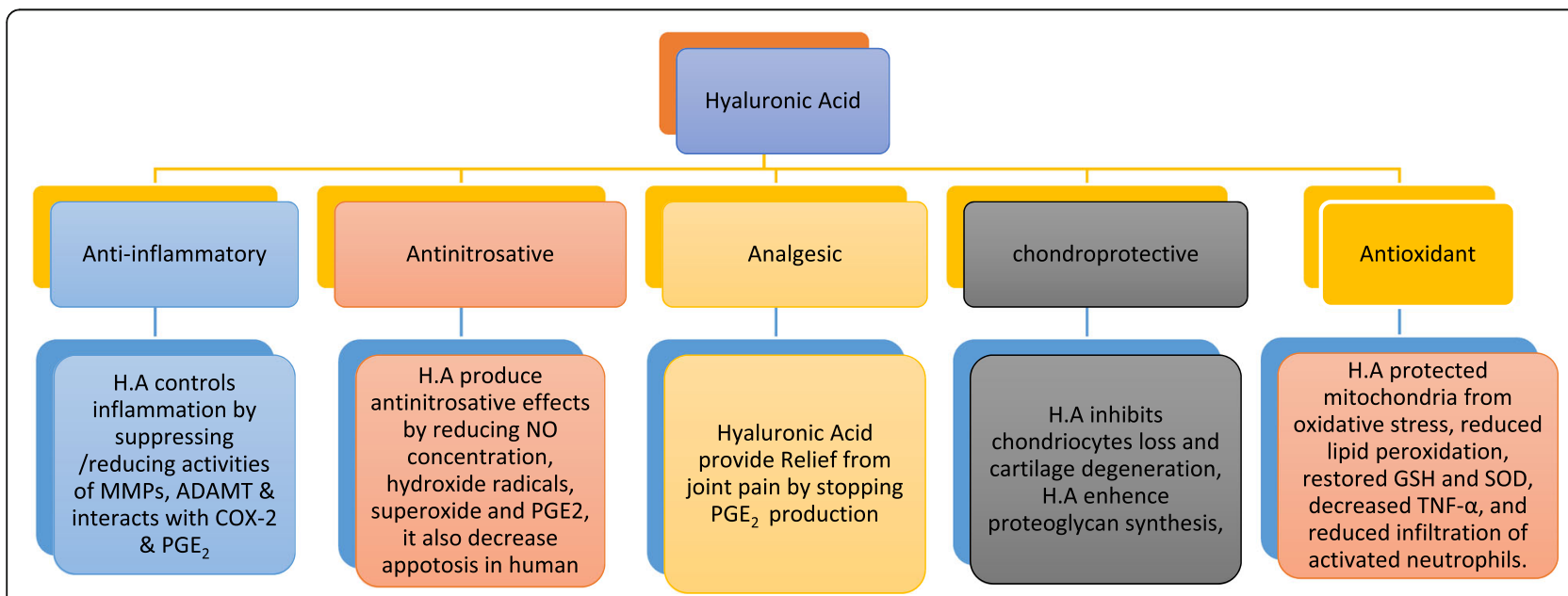

Fig. 4 Schematic diagram representing hyaluronic acid; some important medicinal properties [36]: SOD, superoxide dismutase; GSH, reduced glutathione; TNF-a, tumor necrosis factor alpha; H.A., hyaluronic acid; $\mathrm{PGE}_{2}$, prostaglandin E2; NO, nitric oxide; MMPs, matrix metalloproteinase; ADAMT, a disintegrin and metalloproteinase with thrombospondin motifs; COX-2, cyclooxigenase-2 
Table 1 Various forms, methods, and applications of nanoformulation of curcumin with hyaluronic acid

\begin{tabular}{|c|c|c|c|c|c|}
\hline $\begin{array}{l}\text { S. } \\
\text { no. }\end{array}$ & $\begin{array}{l}\text { Cur-HA } \\
\text { nanoformulation }\end{array}$ & Description & Used for & Outcomes & Ref \\
\hline 1 & Micelles & $\begin{array}{l}\text { A micella or micelle referred as an aggregate of } \\
\text { amphiphilic surfactant molecules that } \\
\text { spontaneously dispersed in water producing } \\
\text { colloidal suspension. }\end{array}$ & $\begin{array}{l}\text { Rheumatoid arthritis, } \\
\text { osteosarcoma, skin, } \\
\text { pancreatic cancer }\end{array}$ & $\begin{array}{l}\text { Curcumin-hyaluronic acid loaded micelles have } \\
\text { demonstrated expected results when applied in } \\
\text { various conditions treatment, it proved antioxidant, } \\
\text { anti-cancerous, and anti-inflammatory }\end{array}$ & $\begin{array}{l}{[37,} \\
40- \\
42]\end{array}$ \\
\hline 2 & Nanoparticles & $\begin{array}{l}\text { Nanoparticles, which are more than } 1000 \text { times } \\
\text { smaller as compared to the average human body } \\
\text { cell and have approximately } 1-100 \text { nm diameter. } \\
\text { They have unique chemical, biological, and phys- } \\
\text { ical properties suitable for the drug delivery. }\end{array}$ & $\begin{array}{l}\text { Cancer, breast } \\
\text { cancer, colon cancer }\end{array}$ & $\begin{array}{l}\text { Nanoparticles conjugated with curcumin and } \\
\text { hyaluronic acid demonstrated better effects } \\
\text { against tumor and cancerous cells. }\end{array}$ & प \\
\hline 3 & Liposomes & $\begin{array}{l}\text { Liposomes are small spherical sac of phospholipid } \\
\text { bilayer molecules bounding aqueous solution; } \\
\text { make closely resembles the plasma membrane of } \\
\text { the cell. Liposomes are specially formed artificially } \\
\text { for the delivery of drugs and certain substances to } \\
\text { the tissues. }\end{array}$ & $\begin{array}{l}\text { Various pulmonary } \\
\text { disorders and lung } \\
\text { cancer }\end{array}$ & $\begin{array}{l}\text { Liposomes improved the ability of curcumin to } \\
\text { protect from oxidative stress and enhanced cell } \\
\text { relative metabolic activity up to } 120 \%\end{array}$ & [46] \\
\hline 4 & Pullulan & $\begin{array}{l}\text { Pullulan is a maltotriose unit containing water- } \\
\text { soluble polysaccharide polymer, chemically well } \\
\text { known as } a-1,4-; a-1,6-\text { glucan. Naturally, pullulan is } \\
\text { derived from the starch of the fungus Aureobasi- } \\
\text { dium pullulans. }\end{array}$ & $\begin{array}{l}\text { Wound healing and } \\
\text { skin injuries }\end{array}$ & $\begin{array}{l}\text { Cur-HA-SPu polymer has many advantages, like } \\
\text { fast hemostasis ability, antimicrobial activity, } \\
\text { maximum swelling ratio, antioxidant properties, } \\
\text { and better cyto and hemocompatibility }\end{array}$ & [47] \\
\hline 5 & Conjugates & $\begin{array}{l}\text { The compound developed by the covalently } \\
\text { joining of hyaluronic acid and curcumin that } \\
\text { bound especially referred to as Cur-HA conjugate. } \\
\text { Curcumin conjugation with hyaluronic acid in- } \\
\text { creases its solubility and bioavailability. }\end{array}$ & $\begin{array}{l}\text { Myofibroblasts in } \\
\text { joint contracture, } \\
\text { wound healing and } \\
\text { skin injuries }\end{array}$ & $\begin{array}{l}\text { Cur-HA-conjugate decreased oxidative damage, } \\
\text { enhanced cell proliferation, antibacterial activities, } \\
\text { and also improved migration of cells on scratch } \\
\text { wounds. } \\
\text { HA-Cur conjugate developed the effects on a } \\
\text { molecular target for PTGER2 in the treatment of } \\
\text { joint contracture }\end{array}$ & $\begin{array}{l}{[28,} \\
48]\end{array}$ \\
\hline 6 & Cyclodextrin & $\begin{array}{l}\text { Cyclodextrins belong to the family of cyclic } \\
\text { oligosaccharides, can be synthesized through } \\
\text { enzymatic conversion from starch. }\end{array}$ & $\begin{array}{l}\text { Cancer cells, wound } \\
\text { infections, antibiotics }\end{array}$ & $\begin{array}{l}\text { Curcumin-cyclodextrin application provides } \\
\text { effective cytotoxicity and anti-cancer activities. One } \\
\text { of its forms was used as a topical antibiotic for the } \\
\text { treatment of wound infections. }\end{array}$ & \\
\hline 7 & Nanogel & $\begin{array}{l}\text { A nanogel is a hydrogel with crosslinked network } \\
\text { of hydrophilic polymers. The particular } \\
\text { composition and structure of nanogel provide a } \\
\text { platform for curcumin storage and release. }\end{array}$ & $\begin{array}{l}\text { Cancerous cells, } \\
\text { Alzheimer's disease }\end{array}$ & $\begin{array}{l}\text { It initiated the natural death of cancer cells, by } \\
\text { suppressing the expression of TNF-a, COX- } 2 \text {, and } \\
\text { NF- } \mathrm{KB} \text { cellular targets. Inhibition of amyloid } \beta- \\
\text { protein }(A \beta) \text { aggregation for the prevention and } \\
\text { treatment of Alzheimer's disease. }\end{array}$ & \\
\hline
\end{tabular}

bioavailability of curcumin and therapeutic potential on rheumatoid arthritis treatment. They reported, curcumin-hyaluronic acid nanomicelle presented low cytotoxicity to the experimental animals, good biocompatibility to chondrocytes, excellent anti-inflammatory results, and decreased cytokines. While hyaluronic acid presented the main component of the extracellular matrix by providing lubrication to joints for reducing friction in joints, thus, effectively protect joints from damages [37]. In another study, $\mathrm{Xi}$ et al. developed curcumin-loaded micelles by using alendronatehyaluronic acid-octadecanoic acid (ALN-HA-C18) as an amphiphilic material. Their result showed a sustained mannered release of curcumin from these micelles. The hydroxyapatite affinity experiment presented that curcumin-loaded alendronate-hyaluronic acidoctadecanoic acid micelles exhibited a high affinity to the bone and higher cytotoxic activity against MG-63 cells compared to free curcumin treatment. They presented their conclusion that curcumin-loaded ALN-HAC18 micelles effectively developed anti-tumor properties in osteosarcoma bearing mice as compared with free curcumin [40]. So, these above studies suggest the use of applications of micelles of curcumin-hyaluronic acid for the treatment of rheumatoid arthritis and osteosarcoma bone disorder because of their delivery of curcumin the hydrophobic anti-cancer drug to targeted cancerous cells.

\section{Nanoparticles}

Another application that is most often is using in advanced modern biotechnology, medicinal sciences, and pharmacology for controlled and targeted drug delivery is the use of nanoparticles [55]. Previously, many researchers have used the formation of nanoparticle for the therapeutic applications of water-soluble curcumin in various studies, like solid lipid, gold, magnetic, and albumin-based nanoparticles. Although polymeric nanoparticles are better among these formations because of their small size and biocompatibility, polymeric nanoparticles are more than 1000 times smaller as compared to the average human body cell and have approximately 1- 
$100 \mathrm{~nm}$ diameter [56]. These nanoparticles have unique chemical, biological, and physical properties which make them suitable applications for drug delivery and allow them to circulate in the blood for a long time [57].

Manju and Sreenivasan developed water-soluble Cur-HA conjugated gold nanoparticles that show increased targeting efficacy at cancer cells through folate receptors and receptors of hyaluronic acidmediated endocytosis. The delivery system of a synthetic compound of polyethylene-glycol-folic acid conjugated with hyaluronic acid curcumin at gold nanoparticle PF.HA-Cur@AuNPs increased the effective supply of curcumin to the perinuclear or nuclear region of cells of cancer [43]. Chen et al. developed curcumin-encapsulated hyaluronic acid-polylactide nanoparticles CEHPNPs to elicit cytotoxicity toward activated hepatic stellate cells aHSCs and attenuate thioacetamide (TAA)-induced rat hepatic fibrosis. Their drug scheme induced significant aHSC cell death without affecting parenchymal cells or hepatic epithelial cells, and quiescent HSCs. They concluded that therapeutic effects of CEHPNPs are as effective as the group treated with the same curcumin dose intensity in vivo. The advantages of satisfactory therapeutic effects and greater biosafety suggest CEHPNPs is a potential application to be applied in treating hepatic fibrosis [58]. Ghosh et al. delivered curcumin through mesoporous silica nanoparticle (MSN) conjugated with hyaluronic acid (HA) on the surface, formulate MSN-HA-Cur nanocompounds. They reported that along with curcumins-hyaluronic acid also expressed its anti-cancer ability at CD-44 receptors in cancerous cells. They showed their result that MSNHA-Cur nanoparticle based nanoformulation is also a possible effective application for the treatment of breast cancer [44]. Singh et al. reported the results of their study on the cytotoxic efficacy of modified silica nanoparticle curcumin complex conjugated with hyaluronic acid (HA-SiNp-cur) and hyaluronic acid-free silica nanoparticle-curcumin complex in human colon carcinoma (colo-205) cells. Their study has shown that HA-SiNp-cur-enhanced uptake of curcumin through CD44-mediated endocytosis and developed improvement in cytotoxicity in carcinoma cells of the colon. The curcumin-hyaluronic acid complex also presented better distribution and internalization in spheroids of colon carcinoma as compared to the free hyaluronic acid complex, apparently due to exocytosis of endocytosed silica nanoparticle. Singh et al. concluded that these nanomaterials of curcumin and hyaluronic acid are more potent as compared with hyaluronic acid-free complexes for inhibiting growth as well as invasion of tumor spheroids [45]. Ji et al. developed surface reformed hydrophilic HA@Cur-NCs through the modification of hyaluronic acid on the surface of curcumin-nanocrystals. That is a nanoparticle formulation of curcumin that exhibits prolonged biodistribution of curcumin for targeting breast cancer cells. This formulation has the advantages of being a high drug loading capacity and stability [59]. Abovementioned researches are suggesting that the fabricated nanomaterials of curcumin-hyaluronic acid or biochemical compounds approach in nanoparticles is also an effective strategy in a various disorder like breast cancer, metastasis, and hepatic cancers.

\section{Liposomes}

One of the widely used applications of curcumin delivery in the body system is liposome. The liposomes are the small spherical sac of phospholipid bilayer molecules bounding aqueous solution; make closely resembles the plasma membrane of the cell. Liposomes are specially formed artificially for the delivery of drugs and certain substances to the tissues. Liposome gives the following advantages like biodegradation, biocompatibility, better solubility, low toxicity, high stability, controlled distribution, targeting specific cells, flexibility, and easy preparation [60]. Here, we mention only one study of fabricated nanomaterial of curcumin-hyaluronic acid in liposomes.

Manconi et al. reported that the liposome of curcumin-hyaluronan was applied for improving nebulization performances and lung antioxidants, where polymer surface modified liposomes were formed to boost retention and bioavailability of curcumin into tissues of the lung [46]. Here, negatively charged hyaluronic acid HA has been used to cover liposomes and increase mucoadhesive properties of liposomes. Further, hyaluronic acid improves the stability of liposome and bioavailability of curcumin due to its adhesive properties. In this research work, liposomes of curcumin with hyaluronic acid were fabricated through a mixture of soybean phospholipids and curcumin where its membrane was covered with sodium hyaluronate.

\section{Pullulan}

Pullulan is a maltotriose unit containing water-soluble polysaccharide polymer, chemically well known as $\alpha-1$, $4-; \alpha-1,6$-glucan'. The pullulan structure is based on $\alpha-1$, 4 glycosidic bond of three glucose units in maltotriose, while consecutive units of maltotriose are linked with each other by a $\alpha-1,6$ glycosidic bond [61]. Naturally, pullulan has derived from the starch of the fungus Aureobasidium pullulans, where pullulan is important for the resist desiccation and predation by cells. Pullulan can be modified into a polymer of partially soluble or fully soluble in water. Pullulan has the following properties like oxygen barrier, moisture retention, and 
antifungal growth [62]. It also exhibited antienzymatic activities against certain enzymes like glucose oxidase, amylases, $\beta$-glucosidase, invertase, and some proteolytic enzymes. The main property of pullulan for conjugating Cur-HA is that of its high solubility in water; hence, it is applied for a carrier of curcumin and it helps in the controlled delivery of curcumin and hyaluronic acid to plasma. The application of pullulan in the field of biotechnology and medicinal science has developed a better expansion due to its nontoxic, nonimmunogenic, inert nature, and biocompatibility.

Duan et al. reported the fabrication of curcuminhyaluronic acid-succinylated pullulan (Cur-HA-SPu), the film material of antioxidative and antibacterial by using DMAP (4-dimethyl aminopyrimidine) as a catalyst, 1ethyl-3(d-dimethyl aminopropyl)-1-carbodiimide hydrochloride as a dehydrating agent and formamide as the solvent. This study suggests that Cur-HA-SPu polymer has many advantages, like fast hemostasis, maximum swelling ratio, antimicrobial, antioxidant properties, better cyto, and hemocompatible properties. Through the experimental study on Wistar rats, Cur-HA-SPu polymer presented accelerating healing of wound as well as proved to have potential effects in the treatment of skin injures [47].

\section{Conjugates}

These are the compounds developed by the covalently joining of hyaluronic acid with curcumin that bound especially referred to as Cur-HA conjugate. Curcumin conjugation with hyaluronic acid increases its solubility and bioavailability.

$\mathrm{Yu}$ et al. synthesized hyaluronic acid with curcumin (HA-Cur) conjugates for the treatment of myofibroblasts in joint contracture. This study presents results that HA-Cur conjugate regulates methylation of prostaglandin E receptor 2 (PTGER2) and inhibit TGF-b signaling pathway that significantly attenuated the fibrotic functions of the myofibroblast in joint contracture in vitro. This study indicates that HA-Cur conjugate has a molecular target for PTGER2 and has shown better results in the treatment of joint contracture [48]. In another study, Sharma et al. reported the synthesis of another type of Cur-HA conjugate nanoparticle for wound healing. They carried out their study on human keratinocyte $\mathrm{HaCaT}$ cells for antioxidant activity, proliferation, and healing of the wound. The result of this study showed that Cur-HA-conjugate decreased oxidative damage, enhanced cell proliferation, antibacterial activities, and also improved migration of cells on scratch wound areas. Sharma et al. suggest Cur-HA conjugation is a promising formulation for enhancing healing efficacy [28].

\section{Cyclodextrins}

Cyclodextrins belong to the family of cyclic oligosaccharides, which are mainly composed of six (a-), seven (b-), or eight (g-) D-glucopyranose units linked through a 1,4glycosidic bond to form macrocycles. Cyclodextrins (CD) can be synthesized through enzymatic conversion from starch. These compounds may be used in various applications like food, pharmaceutical, chemical industries, agriculture, and environmental engineering as well as for drug delivery [63], due to their ability to increase drug stability and solubility and designate drugs in their active form to the targeted cells. Among various types of cyclodextrins, i.e., alpha, beta, and gamma-cyclodextrins, gamma-cyclodextrin is a more attractive selection due to the larger size of its cavity and higher solubility compared with other cyclodextrin types. However, the production of gamma-cyclodextrin is expensive and timeconsuming compared with other cyclodextrin types that might limit its application. Since the synthesis of gamma-cyclodextrins can be expensive and timeconsuming. In comparison, the beta-cyclodextrin type is conventionally used because of the lower price [64, 65]. Recently, many researchers reported curcumin delivery system with $\beta$-cyclodextrin which expresses the significance of $\beta$-cyclodextrin in the curcumin delivery system. In some reports, researchers have used curcumin and hyaluronic acid conjugated with $\beta$-cyclodextrin, an active targeting $\beta$-cyclodextrin-modified hyaluronic acid (HA$\mathrm{CD})$ and drug-drug conjugates curcumin-oxoplatin (Cur-Pt) [66].

Bai et al. reported the synthesis of supramolecular self-assemblies with active targeting $\beta$-cyclodextrinmodified hyaluronic acid (HA-CD) and drug-drug conjugates curcumin-oxoplatin (Cur-Pt). In these $\beta$ cyclodextrin compounds, the host-guest combination between $\beta$-cyclodextrin and curcumin was developed and utilized to produce specific-responsive drug delivery systems. Here, curcumin acted as a guest molecule as well as the anti-cancer drug that strengthened the bio-medical application of supramolecular polymers. Their study through the basic cell experiment proved its effective cellular toxicity and active targeting ability of the constructed selfassemblies [49]. Wikene et al. reported the preparation of solid dispersions of curcumin with methyl- $\beta$ cyclodextrin $\mathrm{M} \beta \mathrm{CD}$ and hyaluronic acid (HA) by lyophilization that lyophilizate expressed properties like being rapidly dissolvable in aqueous solution with a high curcumin drug load. Further solid state lyophilizates proved as thermally stable, but photolabile. These lyophilizates expressed in dissolution themselves as supersaturated solutions of curcumin which later presented the best phototoxic results on both gram-positive and gram-negative bacteria. Here, 
Wikene et al. suggested lyophilate of curmin with $\mathrm{M} \beta \mathrm{CD}$ and $\mathrm{HA}$ as an alternative topical antibiotic for the treatment of wound infections [50].

\section{Nanogel}

A nanogel is a hydrogel with a crosslinked network of hydrophilic polymers. These nanogels are made up of biopolymers or synthetic polymers that are either chemically or physically crosslinked $[67,68]$. Nanogel is usually in the 10 to 100 of nanometers in diameter. The particular composition and structure of nanogel provide a platform for drug storage and release [69]. Many researchers have reported curcumin and hyaluronic acid nanogel applications.

Wei et al. designed a nanogel of curcumin conjugated with cholesteryl-hyaluronic acid CHA-CUR, which demonstrated at oral administration, anti-cancer activities, even it has enhanced cellular permeability of curcumin. These nanogels have expressed their capability of targeted delivery to CD44-expressing drug-resistant cancer cells. It initiated a natural death of cancer cells, by suppressing the expression of TNF- $\alpha, \mathrm{COX}-2$, and NF- $\mathrm{kB}$ cellular targets of free curcumin [70]. Seok et al. in their study developed curcumin encapsulated hyaluronic acid linked with zein nanogels (HA-Zein NGs) for the delivery of curcumin at targeted cancerous cells. Their studies showed high anti-cancer activity against the CT26 cells [51]. Jiang et al. reported treatment of Alzheimer's disease through curcumin-epigallocatechin-3-gallate (EGCG) by modified hyaluronic acid self-assembled nanogels. This nanogel showed great inhibition of the amyloid $\beta$-protein $(A \beta)$ aggregation for the prevention and treatment of Alzheimer's disease [52]. So nanogels may be actively used as a vector for delivery of drugs to actively release on targeted cells.

\section{A comparative analysis and efficacy of nanomaterial of curcumin-hyaluronic acid with nanocurcumin}

The different physical and chemical composition of synthetic nanomaterials of curcumin with hyaluronic acid determine their characteristics and efficacy where they were applied. Above discussed various methods like micelles, liposomes, pullulans, and nanogel are used for carriers of curcumin and hyaluronic acid to targeted cells even in some studies, hyaluronic acid itself is used as a carrier of curcumin to the targeted areas, where the size, surface area, surface charge, and hydrophobicity are important characteristics of consideration to form nanomaterials of curcumin-hyaluronic acid; however, hyaluronic acid has its own therapeutic effects. As compared with the native curcumin which has low solubility and availability in the body even various studies show 10-100 $\mathrm{nm}$ size nanoparticles of curcumin mostly have been used in medicinal applications and clinical trials but the current studies determine the nanomaterials of curcumin with hyaluronic acid has ideal properties that further improve the efficacy of curcumin in its therapeutic activities [71]. Here, it is worth mentioning that curcumin possessing a wide range of pharmacological activities that include anti-cancer, antiviral, antifungal, antioxidant, antiangiogenic, and anti-inflammatory properties, so applying curcumin's nanomaterials with hyaluronic acid is considering an ideal choice as compared to normal curcumin. It was also found that applying nanomaterials of curcumin with hyaluronic acid enhances systemic bioavailability in tissue and plasma as compared to the free curcumin. So far, various attempts made to encapsulating curcumin into various nanoformulations with hyaluronic acid. The various synthesized nanoformulations of curcumin with hyaluronic acid biochemicals have been mainly used as ameliorative therapy of arthritis, tumor, neurological disorders, and wound healing. The bioavailability and efficacy of nanocurcumin increase with the addition of the particular extracellular matrix component the hyaluronic acid, which plays many key roles in different physiological functions, particularly in joints, like lubrication, tissue's hydration, and the interactions between proteins and proteoglycans of the extracellular matrix [72]. For its various therapeutic roles already discussed above hyaluronic acid has been selected as an ideal carrier of curcumin to prepare CurHA nanomaterials. The certain comparative analysis of curcumin and nanomaterials of curcumin with hyaluronic acid is present in Table 2.

\section{Therapeutic applications of nanomaterials of curcumin and hyaluronic acid}

The nanomaterials of curcumin-hyaluronic acid biomaterials through studies have proved a promising therapeutic application with valuable properties like anticancer, anti-inflammatory, antiamyloid, antioxidant, antimicrobial, and antifibrosis with the potential treatment of many human diseases. In the below section, therapeutic applications of nanocurcumin-hyaluronic acid biomaterials are discussed.

\section{Anti-cancer effects}

Nanomaterials of curcumin with hyaluronic acid have been recognized through various researches as a successful anti-cancerous application on various animal models including humans. It acted as an effective drug against human breast, lung, liver, and pancreatic cancers due to the apoptosis inducing capability of curcumin, which prevents cancer cell growth and suppression of cell cycle development [84], and HA which helps delivery of curcumin at targeted cells. Previous studies illustrate that curcumin prevents the development of metastasis of 
Table 2 Comparative analysis of nanomaterials of curcumin and hyaluronic acid therapy with curcumin therapies

\begin{tabular}{lll}
\hline Activity & Curcumin only & Cur-H.A \\
\hline $\begin{array}{l}\text { Breast } \\
\text { cancer }\end{array}$ & $\begin{array}{l}\text { Curcumin: applied as oral } \\
\text { dose [73] }\end{array}$ & Hybrid nanoparticles [74] \\
& & \\
$\begin{array}{lll}\text { Colorectal, } \\
\text { colorectal } \\
\text { cancer }\end{array}$ & $\begin{array}{l}\text { Curcumin: nanoformulations } \\
\text { and with chemotherapy }\end{array}$ & $\begin{array}{l}\text { HA-CPT/CUR-NPs [77], and HA-SiNP- } \\
\text { agents [75, 76] }\end{array}$
\end{tabular}

\section{Description}

Yang et al. applied combination therapy with paclitaxel (PTX), a chemotherapeutic agent and curcumin using HA-hybrid NPS that expressed a potential strategy for inhibiting breast tumor growth by killing breast cancer stem cells (bCSCs) and nonCSCS.

Xiao et al. reported curcumin with hyaluronic acid and chemotherapy agents like HA-CPT/CUR-NPs is more effective than usual chemotherapic procedures against colon- 26 cells [77]. Singh et al. reported silica modified curcumin complex conjugated with hyaluronic acid (HA-SiNp-cur) in human colon carcinoma colo205 cells. Their study has shown improvement in cytotoxicity in carcinoma cells of the colon [45].

Pancreatic Curcumin/gelatin-blended Nanomicelles of HA-SMA-CDF cancer nanofibrous mat [78]

Kesharwani et al. reported the significant effect of nanomicelles of hyaluronic acid-styrene maleic acid-anti-cancer agent, 3,4difluorobenzylidene curcumin HA-SMA-CDF in inhibition of proliferation of NF-KB, the cancer-causing cells. Their results suggest $\mathrm{HA}$ and Cur nanomicelles have great implications in treating pancreatic cancers [41].

\section{Diabetic Curcumin with diabetes Curcumin and Hyaluronic} wound therapies [79-81] formulation reported only for the diabetic wound healing

Hussain et al. fabricated curcumin and resveratrol carrier nanoparticles CUR-REV-CS-NPs functionalized with HA and optimized their physicochemical characteristics, storage stability, thermal stability, and release kinetics for diabetic wound healing that would reduce the frequency of topical application for the management of diabetic wound, improve therapeutic efficacy, increase localized targeting and prolong the residence of curcumin and resveratrol at the target site $[28,82]$.

Arthritis Curcumin oral dose [83] Hyaluronic acid/curcumin (HA/ Cur) nanomicelle

Fan et al. constructed a nanomicelle of HA/Cur for potential therapy of rheumatoid arthritis. The newly found drug showed excellent anti-inflammatory effect in mice experiment. The constructed drug can reduce the expression of related cytokines and VEGF, developing in a targeted inhibition of the inflammatory response [37].

Wound By various methods Cur-HA-SPu
Curcumin with hyaluronic acid pullulan Cur-HA-SPu showed better results in wound healing, through producing no cytotoxicity, rapid cell proliferation, antioxidant, and antibacterial activities [47]. cancer cells and prevents the attack of cancer cells on normal cells and tissues. Curcumin acts on the genes of tumor growth and proliferation by suppressing their expression like genes of bcl-2, cyclin D1, c-Myc, and Bcl$x L$. It has been well observed that curcumin inhibits the activity of nuclear factor-kappa (NF-kB) through various studies [85]. Here, the hyaluronic acid has been used for enhancing the bioavailability and degradability of curcumin even for delivery on targeted cancer cells that is due to hyaluronic acid interacts with CD44, to initiate many cellular activities like cell differentiation, proliferation, migration, angiogenesis, survival, and protease docking on the plasma membrane [86]. While hyaluronic acid's other binding receptors, such as the receptor for HAmediated motility (RHAMM or CD168), hyaluronan receptor for endocytosis (HARE), and the intracellular adhesion molecule-1 (ICAM-1, or CD54) are involved to start various signaling cascades. Hence, hyaluronic acid has been used in many cancer treatments based on various therapeutic strategies $[87,88]$. Therefore, various combined nanomaterials of curcumin with hyaluronic acid are studied and applying to target cancer cells, which overexpress CD44 and isoforms [89]. Here are some examples of cancer disorders where nanomaterials of curcumin-hyaluronic acid are widely studied.

\section{Osteosarcoma}

Osteosarcoma is a type of bone cancer that develops immature bone. Osteosarcoma is regarded as the common type of bone cancer which develops at the end of long bones, mostly around the knee. The average age of diagnosis is about 25 years; it is more common in males than females [90]. Xi et al. produced curcumin bearing, multifunctional alendronate-hyaluronic acid-octadecanoic acid ALN-HA-C18 micelle. Their study suggests that ALNHA-C18 micelle has a close affinity to bones, which exhibited high cytotoxic activity against MG-63 cells and delayed anti-tumor growth properties in osteosarcoma bearing mice as compared with free curcumin [40]. 


\section{Pancreatic cancer}

According to the available data, pancreatic cancer cost about $4.0 \%$ of all cancer deaths every year worldwide. So, it becomes the fourth most common reason for deaths among other cancer incidences, while the mortality rates due to pancreatic cancer are also increasing in the world [91]. Pancreatic cancer is considered an aggressive kind of cancer thus most of the patients have metastatic or locally advanced pancreatic cancer at their time of diagnosis. The average survival time of pancreatic cancer patients is about 4 months and if there is metastatic then it is only about 2 to 3 months. Unfortunately, the survival rate of pancreatic cancer patients has not still improved [92]. Kesharwani et al. prepared the hyaluronic acid conjugate of styrene-maleic acid (HASMA) use to form micelles with 3, 4-difluorobenzylidene curcumin (CDF). This synthetic compound presented its better results as (i) high curcumin loading with high aqueous solubility; (ii) remarkable biosafety because the use of non-toxic compounds; (iii) proved potent anticancer applications in cell lines of human pancreatic cancer cells; (v) better drug curcumin delivery on CD44 expressing tumor cells; and importantly (iv) inhibition of NF-kB in CD44+ cells [41].

\section{Breast cancer}

Breast cancer worldwide is considered the second leading cause of death among women due to cancer. Its prevention becomes a challenge because it develops through the multi-step process involving multiple cell types. The best approach to prevent this cancer is the early diagnosis [93]. Early diagnosis and early prevention help to survive $80 \%$ of patients [94]. In the recent decade, great efforts have been made to treat breast cancer. Ghosh et al. delivered curcumin through mesoporous silica nanoparticle (MSN) and hyaluronic acid to targeted cancer cells CD-44. This study had developed an effective result by reducing tumor volume in tumor bearing mice [44].

\section{Lung cancer}

Manconi et al. reported curcumin-loaded liposomes modified by coating their surface with hyaluronic acid to support both phyto-drug and vesicles to improve curcumin local efficacy. For the first polymer, positively charged, stiff vesicles, and oligolamellar were obtained using negatively charged, unilamellar, and less stiff vesicles with the second one. Their overall results disclosed that vesicles coated with hyaluronic acid present more suitable to improve lung deposition and to effectively protect A549 cells from the oxidative stress induced by hydrogen peroxide. Cytotoxic effect of samples on A549 cells was assayed for $48 \mathrm{~h}$ by testing different dilutions curcumin-loaded hyaluronan-coated liposomes may represent a potential and safe delivery system for the local treatment of different lung diseases [46].

\section{Colon cancer}

Colorectal and colon cancer, counted as 3rd most common malignant tumor, is linked with high mortality and morbidity; according to the available data, this cancer account for over 1.4 million new cases and approximately more than half a million deaths worldwide each year $[95,96]$. Colon cancer is considered as a complex disease involving various cellular pathways [97]. Therefore, many researchers have proposed hyaluronic acid with curcumin nanomaterial-based combination chemotherapy, targeting different cellular pathways, as a promising alternative strategy.

Xiao et al. present hyaluronic acid functionalized PLGA NPs as carriers to co-deliver camptothecin CPT and curcumin CUR for combination chemotherapy of colon cancer. Their studies showed that both drugs were released instantaneously and were successfully taken up by cells. These studies determine that the excellent colon cancer cell-targeting ability of HA-CPT/CUR-NPs promotes colon cancer-targeted delivery and synergistic activity against colon-26 cells [77].

\section{Rheumatoid arthritis}

Rheumatoid arthritis (RA) is a chronic autoimmune disorder that particularly affects joints of a person with the characteristics of painful, swollen, and warm joints, commonly, the hands and wrists on both sides of the body and it may also affect some other parts of the body [98]. Arthritis involves inflammation of joints or hyperplasia of the synovial membrane, pain, swollen, warmth, tender, and stiffness limits the movement of joints ultimately dysfunction [99]. Multiple joint arthritis may also be developed with the passing of time and age from small joints of the cervical spine, feet, and hands to larger knee and shoulder joints [100]. Although the reasons for developing rheumatoid arthritis are not clear, however, it is postulated that the effects of genetic and environmental factors both are involved. Various studies indicate that various cytokines (IL-1 TNF- $\alpha$, IL-6, and IL-8) have an important role in the pathogenesis of rheumatoid arthritis; along with cell adhesion molecules, chemokines, and matrix metal loproteinase [101]. The diagnosis procedures mainly depend on the sign and symptoms of the person, X-rays, and laboratory testing [102]. Therapies or treatment of rheumatoid arthritis is mainly focusing on reducing pain, reducing inflammation, and improving the physiological functions of joints. Typical drugs of rheumatoid arthritis have many side effects. In this regard, curcumin, hyaluronic acid conjugate therapy has developed better results [37]. Fan et al. have constructed curcumin hyaluronic acid nanomicelle for 
rheumatoid arthritis. By experiments on rats, it has developed better results by producing biocompatibility that initiates the proliferation of chondrocytes, when injected into the rats. That nanomicelle therapy significantly lowered the edema of the arthritic rats and decreased friction between the cartilages of joints [37].

\section{Myofibroblasts joint contracture}

Joint contracture is a condition in which joints became tighten and immobilized; this may cause deformity of the joint. The joint contraction is followed by symptoms of pain and loss of movement in the joint. The contraction in the joint may be developed after an experience of joint surgery or long time immobilization, which leads to the irreversible disability of the joint $[103,104]$. Joint contracture affects at least $34 \%$ of patients after joint surgery or immobilization of joints [105]. The pathological changes which cause the contracture in the joint are myofibroblasts generation, deposition, and the proliferation of extracellular matrixes in the joint capsule. Myofibroblasts in joint contracture is a fibrotic problem that may induce by trauma and joint immobilization with characteristics of an excessive myofibroblast proliferation in the joint capsule [106]. Therefore, Yu et al. developed Cur-HA conjugate molecules that suppressed myofibroblast development, treatment, and prevented joint contracture in their study [107].

\section{Skin and wound healing}

According to various literature, any destruction, damage, or cut of the skin is called a "wound" $[108,109]$. Skin wounds remained serious health concerns, especially nonhealing, chronic wounds like, pressure ulcers, diabetic foot ulcers, and venous leg ulcers, which manifests delayed and incomplete pathologically skin healing, presenting the patient to a higher danger of bacterial and fungal diseases [110]. Wounds that continue through the wound healing process without reestablishing functional and anatomic outcomes or that has failed to proceed through a timely sequence of wound healing are chronic non-healing wounds $[111,112]$. A chronic non-healing wound in diabetic persons is one of the most serious issues. Patients who suffer from diabetic wounds can undergo lower-leg amputations, which will bring them about high medical care costs and low quality of life [113].

Practically, all kinds of wounds, including chronic non-healing wounds, required rapid treatment of the wounded area to reduce damage to the skin and underlying tissues for protecting the wounds from secondary infections, enable tissue regeneration, and enhance epithelization [114]. Chronic wounds expose the same characteristics that contain elevated inflammatory markers, high levels of proteases, reduced cellular proliferation, and low growth factor activity [115]. The presence of poor metabolic conditions as well as infections in the patients also results in chronic wounds [116]. Chronic wounds also have high levels of free radicals like hydrogen peroxide and superoxide [117], which may be detrimental to wound healing. Various previous researches have demonstrated that curcumin has an effective antioxidant effect on skin wounds $[118,119]$. These studies prove that curcumin can scavenge free radicals, i.e., ROS and RNS and also modulate the enzyme (GSH, catalase, and SOD) activity to deactivate the free radicals. Curcumin also obstructs ROS-producing enzymes (i.e., lipoxygenase/cyclooxygenase) [85]. As compared with the other antioxidants, curcumin is a unique and potent antioxidant agent as it possesses many forms of functional groups like diketo group, carbon-carbon double bonds, and phenyl rings, in its structure [85]. Jovanovic et al. recognized curcumin as a superb $\mathrm{H}$-atom donor, as it releases the $\mathrm{H}$-atom from the central methylene group, in acidic and neutral aqueous solutions and acetonitrile solutions [120]. In another study, Barclay et al. also described that curcumin is a phenolic chainbreaking antioxidant, and gives the phenolic group of $\mathrm{H}$ atoms [121]. The wound healing activities of curcumin are also attributed to its roles in enhancing cell proliferation, tissue formation [122], remodeling of tissue, deposition of collagen [123]. The roles of curcumin to initiate skin regeneration, cell proliferation, and vascular density have also been well elaborated by many researchers [124]. Therefore, nanoformulation of curcumin with hyaluronic acid, in previous studies produced great results in wound healing, due to the addition of valuable properties of hyaluronic acid with curcumin, as hyaluronic acid contributes good biocompatibility and biological activity in the healing of wounds. Hyaluronic acid has a strong affinity for cell-specific surface marker CD44 [125], which regulate cell growth and differentiation, cell proliferation, and adhesion [126, 127].

Duan et al. formed curcumin-hyaluronic acidsuccinylated pullulan (Cur-HA-SPu) the film material of antioxidative and antibacterial by using DMAP (4dimethylaminopyrimdine) as a catalyst, 1-ethyl-3(ddimehtyl aminopropyl)-1-carbodiimide hydrochloride as a dehydrating agent and formamide as a solvent. The practical tests were carried out in L929 cells that revealed no cytotoxicity and enhanced cell proliferation, antibacterial activities, and antioxidant activity. They observed through animal experiments on Wistar rats, that Cur-HA-SPu film achieve better wound healing result [47].

\section{Neurological disorders}

Previously by various studies, curcumin has been reported as the neuroprotection agent and it is also involved to manage biochemical pathways associated with 
neurodegenerative disorders even stimulation of neural stem cell proliferation and differentiation [128].

\section{Alzheimer's disease}

Alzheimer's disease is a kind of progressive neuron degeneration in the brain, particularly neurons of the hippocampus and cerebral cortex, and the main kind of dementia that begins slowly and gradually worsens over time [129]. Dementia characterizes as difficulties in memory, disturbances in language, and impairments in activities of daily living. It affects about $6 \%$ of the population aged over 65 [130]. As soon as if a person's condition declines, they become unattached from their family and society. Ultimately, Alzheimer's can lead to death if the body lost its functions [131]. Although the causes of Alzheimer's disease are still uncertain, however, several hypotheses have been put forward by researchers [132]. One of these hypotheses is the amyloid hypothesis which suggested that the amyloid $\beta$-protein's aggregation, deposition, and aggregation contribute to cerebral extracellular amyloid plaques which produce neurotoxicity [133]. Thus, using any drug which inhibits the $A \beta$ aggregation would be considered a better strategy to fight against Alzheimer's disease [52]. Among these drugs, the natural plant extract curcumin has received large attention because of its safety and high efficiency in the inhibition of $A \beta$ aggregation [134, 135]. In this regard, Jiang et al. prepared curcumin-epigallocatechin-3-gallate (EGCG) by modified hyaluronic acid self-assembled nanogels. Curcumin-epigallocatechin-3-gallate, the two inhibitors modified with hyaluronic acid, develops a favorable nanostructure CEHA which regulates different inhibition effects. Their study indicates that the synthesis of curcumin-epigallocatechin-3-gallate as a dual inhibitor nanosystem has the potential against $\mathrm{A} \beta$ aggregation and cytotoxicity [52].

\section{Discussion}

Nanomaterials of curcumin and hyaluronic acid study gap and future directions

Nowadays, nanomaterials of curcumin and hyaluronic acid have received great attention for potential therapeutic applications of curcumin and other additional drugs including hyaluronic acid. By the comprehensive study of available literature, it is worth mentioning that nanomaterials of curcumin and hyaluronic acid produced better therapeutic values and have increased pharmacokinetic properties of the curcumin and other drugs if added. In this review article, we have reported through the available literature various formulations and applications of nanomaterials of curcumin and hyaluronic acid which have been developed and are studied in vivo and in vitro on animals and humans that manifest many successful results on targeted diseases and disorders. However, we have mentioned earlier that curcumin is a versatile drug that is being used for so many diseases like, breast cancer, colorectal cancer, lung cancer, pancreatic cancer, prostate cancer, AIDS, Crohn's disease, gastric ulcer, H. pylori infection, inflammatory bowel disease, IBS, peptic ulcer, rheumatoid arthritis, diabetes, vitiligo, atherosclerosis, $\beta$ thalassemia, cholecystitis, gallbladder contraction, renal transplantation, Alzheimer's disease, and others, but nanomaterials of curcumin and hyaluronic acid have been applied for limited diseases as shown in Fig. 5.

This review highlighted here a huge gap of study of nanomaterials of curcumin and hyaluronic acid on many

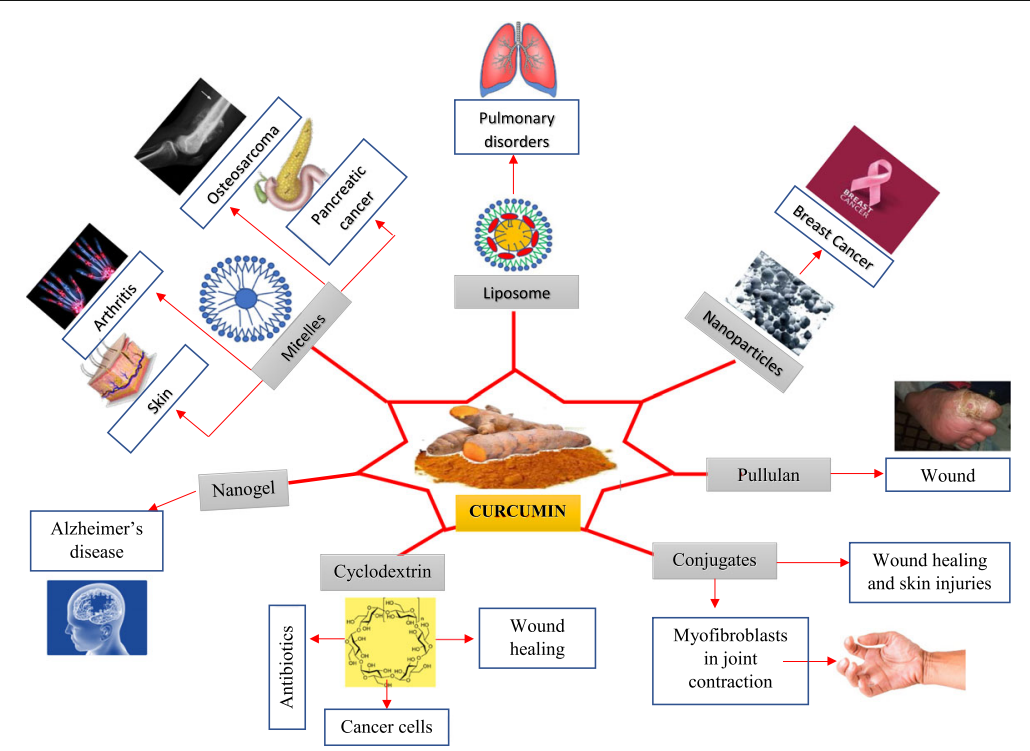

Fig. 5 Various forms of nanomaterials of curcumin with hyaluronic acid and their use against particular diseases and disorders 
curcumin-targeted diseases that should possibly be overcome by further nanomaterials of curcumin-hyaluronic acid experimental and clinical studies. Many challenges are still existing for nanomaterials of curcuminhyaluronic acid to propose it as a promising therapeutic application in human diseases. So far, different applications of nanomaterials of curcumin and hyaluronic acid have been developed like liposome, micelle, conjugate, and pullulan, where the concentration of curcumin and hyaluronic acids are also variable, that ensure tissue specificity, cellular uptake, and the effectiveness of curcumin and other conjugated drugs of applications. This review article, mentioned most of the nanomaterials of curcumin and hyaluronic acid are at the concept stage, and most of the experiments performed under in preclinical models because lack of understanding of the risk of toxicity, allergy, neuroinflammation, and the proper dosage of compounds included in nanomaterials of curcumin and hyaluronic acid. That reasons very few clinical studies have been found in the available literature, but these all studies confirm that nanomaterials of curcumin and hyaluronic acid biomaterial's compounds have better water solubility and physicochemical stability, better bioactive absorption, enhanced pharmacokinetics and bioavailability, better metabolization, strong penetration, and targeting efficacy as compared with the other nanocurcumins.

\section{Conclusion}

However, due to limited clinical trials and experiments of nanomaterials of curcumin and hyaluronic acid on humans and animals, there are substantial gaps in research for the safety and efficacy of nanomaterials of curcumin and hyaluronic acid. Thus, it is an entire need for further clinical trials of nanomaterials of curcumin and hyaluronic acid, whereas in previous studies only curcumin was studied, because curcumin with hyaluronic acid provides better properties for efficacy and activity. Finally, various nanomaterials of curcumin and hyaluronic acid are still in their initial phase to develop their best results. So, it entirely requires serious and committed efforts through the well-organized system of practical and clinical trials that provide the best and enhanced effects and results of nanomaterials of curcumin and hyaluronic acid.

\footnotetext{
Abbreviations

A $\beta$ : Amyloid $\beta$-protein; AD: Alzheimer's disease; aHSCs: Activated hepatic stellate cells; ADAM: A disintegrin and metalloproteinase with thrombospondin motifs; ALN-HA-C18: Alendronate-hyaluronic acidoctadecanoic acid; CD: Cyclodextrin; CD-44: Cluster of differentiation 44; CEHPNPS: Curcumin-encapsulated hyaluronic acid-polylactide nanoparticles; CHA-CUR: Cholesteryl-hyaluronic acid curcumin; COX-2: Cyclooxygenase-2; Cur: Curcumin; Cur-HA-SPu: Curcumin-hyaluronic acid-succinylated pullulan; Cur-Pt: Curcumin-oxoplatin; DMAP: 4-Dimethylaminopyrimdine; DMSO: Dimethyl sulfoxide; EGCG: Curcumin-epigallocatechin-3-gallate; FtsZ: Filamenting temperature-sensitive mutant Z; GS: Reduced glutathione;
}

HA/H.A: Hyaluronic acid; HARE: Hyaluronan receptor for endocytosis; HA-Zein NGs: Hyaluronic acid linked with zein nanogels; HSCs: Hepatic stellate cells; ICAM-1: Intracellular adhesion molecule-1; LOX: Lipoxygenase; MßCD: Methyl$\beta$-cyclodextrin; MMPs: Matrix metalloproteinase; MSN: Mesoporous silica nanoparticle; NC: Nanocrystals; nCUR-HA: Nanocurcumin-hyaluronic acid; NFkB: Nuclear factor kB; NO: Nitric oxide; $\mathrm{PGE}_{2}$ : Prostagladin E2; PF.HACur@AuNPs: Polyethylene glycol folic acid conjugated with hyaluronic acid curcumin at gold nanoparticle; PTGER2: Prostaglandin E receptor 2; RHAM M: Receptor for HA-mediated motility; ROS: Reaction oxygen species; SATA3: Signal transducer and activator of transcription 3; a-Synuclein: A presynaptic neuronal protein that is linked genetically and

neuropathologically to Parkinson's disease; SOD: Superoxide dismutase; TAA: Attenuate thioacetamide; TGF-b: Transforming growth factor beta; TNFa: Tumor necrosis factor alpha

\section{Acknowledgements}

The writeup of this review article was done in the Institute of Biotechnology and Genetic Engineering, University of Sindh, Jamshoro76080, Pakistan. We acknowledge and thank Dr. Habib Ahmed Naqvi, Director of the Institute of Biotechnology and Genetic Engineering, and Dr. Abdul Sattar Qureshi for their moral support and granted access to the internet, laboratory, and required equipment.

\section{Authors' contributions}

TR Charan and MA, both have equal contributions in writing, reviewing, editing, and analyzing this manuscript. M A provided his great motivations and expertise; furthermore, he supervised all the steps of this manuscript writing. MB and AAT provided technical assistance and suggestions in the writeup of the manuscript. GM and SA contribute to data analyzing and the collection of literature. AAM provided a literature survey of curcumin. All the authors read and approved the final manuscript.

\section{Funding}

Not applicable

\section{Availability of data and materials}

All data and materials are available upon request.

\section{Declarations}

Ethics approval and consent to participate Not applicable

\section{Consent for publication \\ Not applicable}

\section{Competing interests}

The authors declare no competing or financial interests.

\section{Author details}

${ }^{1}$ Institute of Biotechnology and Genetic Engineering, University of Sindh, Jamshoro 76080, Pakistan. ${ }^{2}$ Institute of Plant Sciences, University of Sindh, Jamshoro 76080, Pakistan.

Received: 9 March 2021 Accepted: 11 June 2021

Published online: 26 June 2021

\section{References}

1. Hadia AS, Jagarwanti M, Atta MB, Ather HS, Imrana K, Muhammad AB, Jawaid AK, Abdul SQ, Syed AS, Aftab HK (2018) Evaluation of the effects of plant aqueous extracts as anti-diabetic agents on alloxan induced diabetic male rabbits. Afr J Biotechnol 17(36):1111-1118. https://doi.org/10.5897/ajb2 018.16445

2. Rind NA, Dahot MU, Malik SA, Kumar M, Bhutto MA, Rafiq M (2013) Comparative antihyperglycemic activity of aqueous extracts of garlic. Pak J Biotechnol 10:53-62 https://www.researchgate.net/publication/262726555

3. Ahmad RS, Hussain MB, Sultan MT, Arshad MS, Waheed M, Shariati MA, Plygun S (2020) Hashempur MH (2020) Biochemistry, safety, pharmacological activities, and clinical applications of turmeric: a mechanistic review. Evid Based Complement Altern Med 2020:1-14. https:// doi.org/10.1155/2020/7656919 
4. Tomeh MA, Hadianamrei R, Zhao X (2019) A review of curcumin and its derivatives as anticancer agents. Int J Mol Sci 20(5). https://doi.org/10.3390/ ijms20051033

5. Heger M, van Golen RF, Broekgaarden M, Michel MC (2014) The molecular basis for the pharmacokinetics and pharmacodynamics of curcumin and its metabolites in relation to cancers. Pharmacol Rev 66:222-307. https://doi. org/10.1124/pr.110.004044

6. Nelson KM, Dahlin JL, Bisson J, Graham J, Pauli GF, Walters MA (2017) The essential medicinal chemistry of curcumin. J Med Chem 60(5):1620-1637. https://doi.org/10.1021/acs.jmedchem.6b00975

7. Mošovská S, Petáková P, Kaliňák M, Mikulajová A (2016) Antioxidant properties of curcuminoids isolated from Curcuma longa L. Acta Chim Slov 9(2):130-135. https://doi.org/10.1515/acs-2016-0022

8. Adiwidjaja J, McLachlan AJ, Boddy AV (2017) Curcumin as a clinicallypromising anti-cancer agent: pharmacokinetics and drug interactions. Expert Opin Drug Metab Toxicol 13(9):953-972. https://doi.org/10.1080/17425255.2 017.1360279

9. Gupta SC, Patchva S, Aggarwal BB (2013) Therapeutic roles of curcumin: lessons learned from clinical trials. AAPS J 15(1):195-218. https://doi.org/1 0.1208/s12248-012-9432-8

10. Trujillo J, Chirino Yl, Molina-Jijón E, Andérica-Romero AC, Tapia E, PedrazaChaverrí J (2013) Renoprotective effect of the antioxidant curcumin: recent findings. Redox Biol 1(1):448-456. https://doi.org/10.1016/j.redox.2013.09.003

11. Panahi Y, Alishiri GH, Parvin S, Sahebkar A (2016) Mitigation of systemic oxidative stress by curcuminoids in osteoarthritis: results of a randomized controlled trial. J Diet Suppl 13(2):209-220. https://doi.org/10.3109/193 90211.2015.1008611

12. Aggarwal BB, Sung B (2009) Pharmacological basis for the role of curcumin in chronic diseases: an age-old spice with modern targets. Trends Pharmacol Sci 30(2):85-94. https://doi.org/10.1016/j.tips.2008.11.002

13. Nabavi SF, Daglia M, Moghaddam AH, Habtemariam S, Nabavi SM (2014) Curcumin and liver disease: from chemistry to medicine. Compr Rev Food Sci Food Saf 13(1):62-77. https://doi.org/10.1111/1541-4337.12047

14. Bhullar K, Jha A, Youssef D, Rupasinghe $H$ (2013) Curcumin and its carbocyclic analogs: structure-activity in relation to antioxidant and selected biological properties. Molecules 18(5):5389-5404. https://doi.org/10.3390/ molecules 18055389

15. Huang S, Beevers (2011) Pharmacological and clinical properties of curcumin. Bot Targets Ther 1:5. https://doi.org/10.2147/btat.s17244

16. Bhowmik D, Sampath Kumar KP, Chandira M, Jayakar B (2009) Turmeric: a herbal and traditional medicine. Int J Med Res Health Sci https:/www.resea rchgate.net/publication/268268687_Turmeric_A_Herbal_and_Traditional_ Medicine

17. Paulraj F, Abas F, Lajis NH, Othman I, Naidu R (2019) Molecular pathways modulated by curcumin analogue, diarylpentanoids in cancer. Biomolecules 9(7):270. https://doi.org/10.3390/biom9070270

18. Park HH, Ko SC, Oh GW, Heo SJ, Kang DH, Bae SY, Jung WK (2018) Fabrication and characterization of phlorotannins/poly (vinyl alcohol) hydrogel for wound healing application. J Biomater Sci Polym Ed 29(7-9): 972-983. https://doi.org/10.1080/09205063.2017.1374030

19. Yallapu MM, Jaggi M, Chauhan SC (2012) Curcumin nanoformulations: a future nanomedicine for cancer. Drug Discov Today 17(1-2):71-80. https:// doi.org/10.1016/j.drudis.2011.09.009

20. Li B, Takeda T, Tsuiji K, Wong TF, Tadakawa M, Kondo A, Nagase S, Yaegashi N (2013) Curcumin induces cross-regulation between autophagy and apoptosis in uterine leiomyosarcoma cells. Int J Gynecol Cancer 23(5):803808. https://doi.org/10.1097/IGC.0b013e31828c9581

21. Bhatia A, Flamer D, Shah PS, Cohen SP (2016) Transforaminal epidural steroid injections for treating lumbosacral radicular pain from herniated intervertebral discs. Anesth Analg 122:857-870. https://doi.org/10.1213/ANE. 0000000000001155

22. Fonseca-Santos B, dos Santos AM, Rodero CF, Daflon Gremião MP, Chorilli M (2016) Design, characterization, and biological evaluation of curcuminloaded surfactant-based systems for topical drug delivery. Int J Nanomedicine 11:4553-4562. https://doi.org/10.2147/ijn.s108675

23. Ghalandarlaki N, Alizadeh AM, Ashkani-Esfahani S (2014) Nanotechnologyapplied curcumin for different diseases therapy. Biomed Res Int 2014:1-23. https://doi.org/10.1155/2014/394264

24. Yallapu MM, Nagesh PKB, Jaggi M, Chauhan SC (2015) Therapeutic applications of curcumin nanoformulations. AAPS J 17(6):1341-1356. https:// doi.org/10.1208/s12248-015-9811-z
25. Mudagal MP, Janadri S (2019) Curcumin on to hyaluronic acid conjugate enhance cytotoxicity. Asian J Pharm Pharmacol 5(2):281-285. https://doi. org/10.31024/ajpp.2019.5.2.10

26. Neuman MG, Nanau RM, Oruña-Sanchez L, Coto G (2015) Hyaluronic acid and wound healing. J Pharm Pharm Sci 18:53-60. https://doi.org/10.18433/ j3k89d

27. Dicker KT, Gurski LA, Pradhan-Bhatt S, Witt RL, Farach-Carson MC, Jia X (2014) Hyaluronan: a simple polysaccharide with diverse biological functions. Acta Biomater 10(4):1558-1570. https://doi.org/10.1016/j.actbio.2 013.12.019

28. Sharma M, Sahu K, Singh SP, Jain B (2018) Wound healing activity of curcumin conjugated to hyaluronic acid: in vitro and in vivo evaluation. Artif Cells Nanomedicine Biotechnol 46(5):1009-1017. https://doi.org/10.1 080/21691401.2017.1358731

29. Du F, Lou J, Jiang R, Fang Z, Zhao X, Niu Y, Zou S, Zhang M, Gong A, Wu C (2017) Hyaluronic acid-functionalized bismuth oxide nanoparticles for computed tomography imaging-guided radiotherapy of tumor. Int J Nanomedicine 12:5973-5992. https://doi.org/10.2147/IJN.S130455

30. Abou-Okeil A, Fahmy HM, El-Bisi MK, Ahmed-Farid OA (2018) Hyaluronic acid/Na-alginate films as topical bioactive wound dressings. Eur Polym J 109:101-109. https://doi.org/10.1016/j.eurpolymj.2018.09.003

31. You IC, Li Y, Jin R, Ahn M, Choi W, Yoon KC (2018) Comparison of $0.1 \%, 0$. $18 \%$, and $0.3 \%$ hyaluronic acid eye drops in the treatment of experimental dry eye. J Ocul Pharmacol Ther 34(8):557-564. https://doi.org/10.1089/jop.2 018.0032

32. Snetkov P, Morozkina S, Uspenskaya M, Olekhnovich R (2019) Hyaluronanbased nanofibers: fabrication, characterization and application. Polymers 11(12):2036. https://doi.org/10.3390/polym11122036

33. Gold MH (2007) Use of hyaluronic acid fillers for the treatment of the aging face. Clin Interv Aging 2(3):369-376. https://doi.org/10.2147/cia.s1244

34. Biomaterials, Artificial Organs and Tissue Engineering - 1st Edition. https:// www.elsevier.com/books/biomaterials-artificial-organs-and-tissueengineering/hench/978-1-85573-737-2. Accessed 12 Oct 2020

35. Snetkov P, Morozkina S, Olekhnovich R, Hong T, Vu N, Tyanutova M, Uspenskaya M (2020) Based on hyaluronic acid. 13(16). https://doi.org/10.33 90/MA13163476

36. Gupta RC, Lall R, Srivastava A, Sinha A (2019) Hyaluronic acid: molecular mechanisms and therapeutic trajectory. Front Vet Sci 6. https://doi.org/10.33 89/fvets.2019.00192

37. Fan Z, Li J, Liu J, Jiao H, Liu B (2018) Anti-inflammation and joint lubrication dual effects of a novel hyaluronic acid/curcumin nanomicelle improve the efficacy of rheumatoid arthritis therapy. ACS Appl Mater Interfaces 10(28): 23595-23604. https://doi.org/10.1021/acsami.8b06236

38. Hyaluronic acid curcumin - Search Results - PubMed. https://pubmed.ncbi. nlm.nih.gov/?term=hyaluronic+acid+curcumin\&sort=pubdate\&sort_order= asc. Accessed 12 Nov 2020

39. Mudagal MP, Janadri S, Taj N (2019) In-vivo anticancer activity of curcuminhyaluronic acid conjugate. Adv Pharm J 4(3):85-89. https://doi.org/10.31 024/apj.2019.4.3.3

40. Xi Y, Jiang T, Yu Y, Yu J, Xue M, Xu N, Wen J, Wang W, He H, Shen Y, Chen D, Ye X, Webster TJ (2019) Dual targeting curcumin loaded alendronatehyaluronan- octadecanoic acid micelles for improving osteosarcoma therapy. Int J Nanomedicine 14:6425-6437. https://doi.org/1 $0.2147 /$ IJN.S211981

41. Kesharwani P, Banerjee S, Padhye S, Sarkar FH, lyer AK (2015) Hyaluronic acid engineered nanomicelles loaded with 3,4-difluorobenzylidene curcumin for targeted killing of CD44+ stem-like pancreatic cancer cells. Biomacromolecules 16(9):3042-3053. https://doi.org/10.1021/acs.biomac 5 b00941

42. Sahu A, Kasoju N, Bora U (2008) Fluorescence study of the curcumin-casein micelle complexation and its application as a drug nanocarrier to cancer cells. Biomacromolecules 9(10):2905-2912. https://doi.org/10.1021/ bm800683f

43. Manju S, Sreenivasan K (2012) Gold nanoparticles generated and stabilized by water soluble curcumin-polymer conjugate: blood compatibility evaluation and targeted drug delivery onto cancer cells. J Colloid Interface Sci 368(1):144-151. https://doi.org/10.1016/j.jcis.2011.11.024

44. Ghosh S, Dutta S, Sarkar A, Kundu M, Sil PC (2021) Targeted delivery of curcumin in breast cancer cells via hyaluronic acid modified mesoporous silica nanoparticle to enhance anticancer efficiency. Colloids Surf B: Biointerfaces 197:111404. https://doi.org/10.1016/j.colsurfb.2020.111404 
45. Singh SP, Sharma M, Gupta PK (2015) Cytotoxicity of curcumin silica nanoparticle complexes conjugated with hyaluronic acid on colon cancer cells. Int J Biol Macromol 74:162-170. https://doi.org/10.1016/j.ijbiomac.2 014.11 .037

46. Manconi M, Manca ML, Valenti D, Escribano E, Hillaireau H, Fadda AM, Fattal E (2017) Chitosan and hyaluronan coated liposomes for pulmonary administration of curcumin. Int J Pharm 525(1):203-210. https://doi.org/10.1 016/j.ijpharm.2017.04.044

47. Duan Y, Li K, Wang H, Wu T, Zhao Y, Li H, Tang H, Yang W (2020) Preparation and evaluation of curcumin grafted hyaluronic acid modified pullulan polymers as a functional wound dressing material. Carbohydr Polym 238:116195. https://doi.org/10.1016/j.carbpol.2020.116195

48. Yu D, Zhuang Z, Ren J, Hu X, Wang Z, Zhang J, Luo Y, Wang K, He R, Wang $Y$ (2019) Hyaluronic acid-curcumin conjugate suppresses the fibrotic functions of myofibroblasts from contractive joint by the PTGER2 demethylation:1-9. https://doi.org/10.1093/rb/rbz016

49. Bai Y, Liu CP, Chen D, Liu CF, Zhuo LH, Li H, Wang C, Bu HT, Tian W (2020) $\beta$-Cyclodextrin-modified hyaluronic acid-based supramolecular selfassemblies for $\mathrm{pH}$ - and esterase- dual-responsive drug delivery. Carbohydr Polym 246:116654. https://doi.org/10.1016/j.carbpol.2020.116654

50. Wikene $\mathrm{KO}$, Hegge AB, Bruzell E, Tonnesen HH (2015) Formulation and characterization of lyophilized curcumin solid dispersions for antimicrobial photodynamic therapy (aPDT): studies on curcumin and curcuminoids LII. Drug Dev Ind Pharm 41(6):969-977. https://doi.org/10.3109/03639045.2014. 919315

51. Seok H-Y, Sanoj Rejinold N, Lekshmi KM, Cherukula K, Park I-K, Kim Y-C (2018) CD44 targeting biocompatible and biodegradable hyaluronicw acid cross-linked zein nanogels for curcumin delivery to cancer cells: in vitro and in vivo evaluation. J Control Release 280:20-30. https://doi.org/10.1016/j. jconrel.2018.04.050

52. Jiang Z, Dong X, Yan X, Liu Y, Zhang L, Sun Y (2018) Nanogels of dual inhibitor-modified hyaluronic acid function as a potent inhibitor of amyloid ß-protein aggregation and cytotoxicity. Sci Rep 8(1). https://doi.org/10.1038/ s41598-018-21933-6

53. Milovanovic M, Arsenijevic A, Milovanovic J, Kanjevac T, Arsenijevic N (2017) Nanoparticles in antiviral therapy. Antimicrob Nanoarchitectonics Synth Appl:383-410. https://doi.org/10.1016/B978-0-323-52733-0.00014-8

54. Teleanu DM, Chircov C, Grumezescu AM, Teleanu RI (2019) Neuronanomedicine: an up-to-date overview. Pharmaceutics 11(3). https:// doi.org/10.3390/pharmaceutics11030101

55. Biswas AK, Islam MR, Choudhury ZS, Mostafa A, Kadir MF (2014) Nanotechnology based approaches in cancer therapeutics. Adv Nat Sci Nanosci Nanotechnol 5(4): 043001. https://doi.org/10.1088/2043-6262/5/4/043001

56. Rudramurthy G, Swamy M, Sinniah U, Ghasemzadeh A (2016) Nanoparticles: alternatives against drug-resistant pathogenic microbes. Molecules 21(7): 836. https://doi.org/10.3390/molecules21070836

57. Ferrari R, Sponchioni M, Morbidelli M, Moscatelli D (2018) Polymer nanoparticles for the intravenous delivery of anticancer drugs: the checkpoints on the road from the synthesis to clinical translation. Nanoscale 10(48):22701-22719. https://doi.org/10.1039/c8nr05933k

58. Chen YN, Hsu SL, Liao MY, Liu YT, Lai CH, Chen JF, Nguyen MHT, Su YH, Chen ST, Wu LC (2017) Ameliorative Effect of Curcumin-Encapsulated Hyaluronic Acid-PLA Nanoparticles on Thioacetamide-Induced Murine Hepatic Fibrosis. Int J Environ Res Public Health 14(1). https://doi.org/10.33 90/ijerph14010011

59. Ji P, Wang L, Chen Y, Wang S, Wu Z, Qi X (2020) Hyaluronic acid hydrophilic surface rehabilitating curcumin nanocrystals for targeted breast cancer treatment with prolonged biodistribution. Biomater Sci 8:462-472. https:// doi.org/10.1039/c9bm01605h

60. Moballegh Nasery M, Abadi B, Poormoghadam D, Zarrabi A, Keyhanvar P, Khanbabaei H, Ashrafizadeh M, Mohammadinejad R, Tavakol S, Sethi G (2020) Curcumin delivery mediated by bio-based nanoparticles: a review. Molecules 25(3):689. https://doi.org/10.3390/molecules25030689

61. Pullulan - an overview | ScienceDirect Topics. https://www.sciencedirect. com/topics/chemistry/pullulan. Accessed 13 Nov 2020

62. Pinto RJB, Almeida A, Fernandes SCM, Freire CSR, Silvestre AJD, Neto CP, Trindade T (2013) Antifungal activity of transparent nanocomposite thin films of pullulan and silver against Aspergillus niger. Colloids Surf B: Biointerfaces 103:143-148. https://doi.org/10.1016/j.colsurfb.2012.09.045

63. Szejtli J (2003) Cyclodextrins. Chem Funct Prop Food Saccharides 21(2):271290. https://doi.org/10.5458/jag1972.21.151
64. Qiu C, Wang J, Fan H, Bai Y, Tian Y, Xu X, Jin Z (2018) High-efficiency production of $\gamma$-cyclodextrin using $\beta$-cyclodextrin as the donor raw material by cyclodextrin opening reactions using recombinant cyclodextrin glycosyltransferase. Carbohydr Polym 182:75-80. https://doi.org/10.1016/j.ca rbpol.2017.11.014

65. Lin YK, Show PL, Yap YJ, Ariff AB, Mohammad Annuar MS, Lai OM, Tang TK, Juan JC, Ling TC (2016) Production of $\gamma$-cyclodextrin by Bacillus cereus cyclodextrin glycosyltransferase using extractive bioconversion in polymersalt aqueous two-phase system. J Biosci Bioeng 121(6):692-696. https://doi. org/10.1016/j.jbiosc.2015.11.001

66. Guo S (2019) Encapsulation of curcumin into $\beta$-cyclodextrins inclusion: a review. In: E3S Web of Conferences. EDP Sciences. https://doi.org/10.1051/ e3sconf/201913101100

67. Bencherif SA, Siegwart DJ, Srinivasan A, Horkay F, Hollinger JO, Washburn NR, Matyjaszewski K (2009) Nanostructured hybrid hydrogels prepared by a combination of atom transfer radical polymerization and free radical polymerization. Biomaterials 30(29):5270-5278. https://doi.org/10.1016/j. biomaterials.2009.06.011

68. Kabanov AV, Vinogradov SV (2009) Nanogels as pharmaceutical carriers: finite networks of infinite capabilities. Angew Chem Int Ed 48(30):54185429. https://doi.org/10.1002/anie.200900441

69. Wang Z, Zhang RX, Zhang C, Dai C, Ju X, He R (2019) Fabrication of stable and self-assembling rapeseed protein nanogel for hydrophobic curcumin delivery. J Agric Food Chem 67:887-894. https://doi.org/10.1021/acs.jafc.8b05572

70. Wei X, Senanayake TH, Bohling A, Vinogradov SV (2014) Targeted nanogel conjugate for improved stability and cellular permeability of curcumin: synthesis, pharmacokinetics, and tumor growth inhibition. Mol Pharm 11(9): 3112-3122. https://doi.org/10.1021/mp500290f

71. Flora G, Gupta D, Tiwari A (2013) Nanocurcumin: a promising therapeutic advancement over native curcumin. Crit Rev Ther Drug Carrier Syst 30(4): 331-368. https://doi.org/10.1615/CritRevTherDrugCarrierSyst.2013007236

72. Proctor CS, Schmidt MB, Whipple RR, Kelly MA, Mow VC (1989) Material properties of the normal medial bovine meniscus. J Orthop Res 7(6):771782. https://doi.org/10.1002/jor.1100070602

73. Bayet-Robert M, Kwiatkowski F, Leheurteur M, Gachon F, Planchat E, Abrial C, Mouret-Reynier MA, Durando X, Barthomeuf C, Chollet P (2010) Phase I dose escalation trial of docetaxel plus curcumin in patients with advanced and metastatic breast cancer. Cancer Biol Ther 9. https://doi.org/10.4161/ cbt.9.1.10392

74. Yang Z, Sun N, Cheng R, Zhao C, Liu J, Tian Z (2017) Hybrid nanoparticles coated with hyaluronic acid lipoid for targeted co-delivery of paclitaxel and curcumin to synergistically eliminate breast cancer stem cells. J Mater Chem B 5(33):6762-6775. https://doi.org/10.1039/c7tb01510k

75. Howells LM, Iwuji COO, Irving GRB, Barber S, Walter H, Sidat Z, Griffin-Teall N, Singh R, Foreman N, Patel SR, Morgan B, Steward WP, Gescher A, Thomas AL, Brown K (2019) Curcumin combined with FOLFOX chemotherapy is safe and tolerable in patients with metastatic colorectal cancer in a randomized phase Ila trial. J Nutr 149(7):1133-1139. https://doi.org/10.1093/jn/nxz029

76. Wong KE, Ngai SC, Chan K-G, Lee L-H, Goh B-H, Chuah L-H (2019) Curcumin nanoformulations for colorectal cancer: a review. Front Pharmacol 10:152. https://doi.org/10.3389/fphar.2019.00152

77. Xiao B, Han MK, Viennois E, Wang L, Zhang M, Si X, Merlin D (2015) Hyaluronic acid-functionalized polymeric nanoparticles for colon cancertargeted combination chemotherapy. Nanoscale 7(42):17745-17755. https:// doi.org/10.1039/c5nr04831a

78. Cheng T, Zhang Z, Shen H, Jian Z, Li J, Chen Y, Shen Y, Dai X (2020) Topically applicated curcumin/gelatin-blended nanofibrous mat inhibits pancreatic adenocarcinoma by increasing ROS production and endoplasmic reticulum stress mediated apoptosis. J Nanobiotechnology 18(1):126. https://doi.org/10.1186/s12951-020-00687-2

79. Zhang DW, Fu M, Gao SH, Liu JL (2013) Curcumin and diabetes: a systematic review. Evid Based Complement Altern Med 2013:16. https://doi. org/10.1155/2013/636053

80. Pivari F, Mingione A, Brasacchio C, Soldati L (2019) Curcumin and type 2 diabetes mellitus: prevention and treatment. Nutrients 11(8). https://doi. org/10.3390/nu11081837

81. Roxo DF, Arcaro CA, Gutierres VO, Costa MC, Oliveira JO, Lima TFO, Assis RP, Brunetti IL, Baviera AM (2019) Curcumin combined with metformin decreases glycemia and dyslipidemia, and increases paraoxonase activity in diabetic rats. Diabetol Metab Syndr 11(1):33. https://doi.org/10.1186/s13098019-0431-0 
82. Hussain Z, Pandey M, Choudhury H, Ying PC, Xian TM, Kaur T, Jia GW, Gorain B (2020) Hyaluronic acid functionalized nanoparticles for simultaneous delivery of curcumin and resveratrol for management of chronic diabetic wounds: fabrication, characterization, stability and in vitro release kinetics. J Drug Deliv Sci Technol 57:101747. https://doi.org/10.1016/ j.jddst.2020.101747

83. Turmeric for rheumatoid arthritis: benefits and side effects. https://www.hea Ithline.com/health/rheumatoid-arthritis/rheumatoid-arthritis-turmeric\#takea way. Accessed 10 Jan 2021

84. Shishodia S, Sethi G, Aggarwal BB (2005) Curcumin: getting back to the roots. In: Annals of the New York Academy of Sciences. Blackwell Publishing Inc, pp 206-217. https://doi.org/10.1196/annals.1352.010

85. Karthikeyan A, Senthil N, Min T (2020) Nanocurcumin: a promising candidate for therapeutic applications. Front Pharmacol 11. https://doi.org/1 0.3389/fphar.2020.00487

86. Fang XJ, Jiang $H$, Zhao XP, Jiang WM (2011) The role of a new CD44st in increasing the invasion capability of the human breast cancer cell line MCF7. BMC Cancer 11(1). https://doi.org/10.1186/1471-2407-11-290

87. Lokeshwar VB, Mirza S, Jordan A (2014) Targeting hysaluronic acid family for cancer chemoprevention and therapy. Advances in Cancer Research. Academic Press Inc, pp 35-65. https://doi.org/10.1016/B978-0-12-800092-2. 00002-2

88. Jiang D, Liang J, Noble PW (2011) Hyaluronan as an immune regulator in human diseases. Physiol Rev 91(1):221-264. https://doi.org/10.1152/physrev. 00052.2009

89. Ganesh S, lyer AK, Morrissey DV, Amiji MM (2013) Hyaluronic acid based self-assembling nanosystems for CD44 target mediated siRNA delivery to solid tumors. Biomaterials 34(13):3489-3502. https://doi.org/10.1016/j.bioma terials.2013.01.077

90. Osteosarcoma cancer: diagnosis, treatment, research \& support. http://sa rcomahelp.org/osteosarcoma.html. Accessed 28 Nov 2020

91. Fang Y, Yao Q, Chen Z, Xiang J, William FE, Gibbs RA, Chen C (2013) Genetic and molecular alterations in pancreatic cancer: implications for personalized medicine. Med Sci Monit 19:916-926. https://doi.org/10.12659/MSM.889636

92. Zhang Q, Zeng L, Chen Y, Lian G, Qian C, Chen S, Li J, Huang K (2016) Pancreatic cancer epidemiology, detection, and management. Gastroenterol Res Pract 2016. https://doi.org/10.1155/2016/8962321, 2016, 1, 10

93. Siegel RL, Miller KD, Jemal A (2017) Cancer statistics, 2017. CA Cancer J Clin 67(1):7-30. https://doi.org/10.3322/caac.21387

94. Sun YS, Zhao Z, Yang ZN, Xu F, Lu HJ, Zhu ZY, Shi W, Jiang J, Yao PP, Zhu HP (2017) Risk factors and preventions of breast cancer. Int J Biol Sci 13(11): 1387-1397. https://doi.org/10.7150/ijbs.21635

95. Terzić J, Grivennikov S, Karin E, Karin M (2010) Inflammation and colon cancer. Gastroenterology 138(6):2101-2114.e5. https://doi.org/10.1053/j.ga stro.2010.01.058

96. Twelves C, Wong A, Nowacki MP, Abt M, Burris H, Carrato A, Cassidy J, Cervantes A, Fagerberg J, Georgoulias V et al (2005) Capecitabine as adjuvant treatment for stage III colon cancer. N Engl J Med 352:2696-2704. https://doi.org/10.1056/NEJMoa043116

97. Liu C, Zhao G, Liu J, Ma N, Chivukula P, Perelman L, Okada K, Chen Z, Gough D, Yu L (2009) Novel biodegradable lipid nano complex for siRNA delivery significantly improving the chemosensitivity of human colon cancer stem cells to paclitaxel. J Control Release 140:277-283. https://doi. org/10.1016/j.jconrel.2009.08.013

98. Rheumatoid Arthritis | Health Topics | NIAMS. https://www.niams.nih.gov/ health-topics/rheumatoid-arthritis. Accessed 29 Nov 2020

99. Firestein GS (2003) Evolving concepts of rheumatoid arthritis. Nature 423(6937):356-361. https://doi.org/10.1038/nature01661

100. Nygaard G, Firestein GS (2020) Restoring synovial homeostasis in rheumatoid arthritis by targeting fibroblast-like synoviocytes. Nat Rev Rheumatol 16(6):316-333. https://doi.org/10.1038/s41584-020-0413-5

101. McInnes IB, Schett $G$ (2007) Cytokines in the pathogenesis of rheumatoid arthritis. Nat Rev Immunol 7(6):429-442. https://doi.org/10.1038/nri2094

102. Majithia V, Geraci SA (2007) Rheumatoid arthritis: diagnosis and management. Am J Med 120(11):936-939. https://doi.org/10.1016/j.a mjmed.2007.04.005

103. Fischer U, Bartoszek G, Müller M, Strobl R, Meyer G, Grill E (2014) Patients' view on health-related aspects of functioning and disability of joint contractures: a qualitative interview study based on the International Classification of Functioning, Disability and Health (ICF). Disabil Rehabil 36(26):2225-2232. https://doi.org/10.3109/09638288.2014.899634
104. Muscle contracture and stiffening symptoms | UPMC. https://www.upmc. com/services/orthopaedics/conditions-treatments/contractures-and-stiffness. Accessed 9 Dec 2020

105. Clavet H, Hébert PC, Fergusson D, Doucette S, Trudel G (2008) Joint contracture following prolonged stay in the intensive care unit. CMAJ 178(6):691-697. https://doi.org/10.1503/cmaj.071056

106. Abdel MP, Morrey ME, Barlow JD, Kreofsky CR, An KN, Steinmann SP, Morrey BF, Sanchez-Sotelo J (2012) Myofibroblast cells are preferentially expressed early in a rabbit model of joint contracture. J Orthop Res 30(5):713-719. https://doi.org/10.1002/jor.21588

107. Yu D, Zhuang Z, Ren J, Hu X, Wang Z, Zhang J, Luo Y, Wang K, He R, Wang $Y$ (2019) Hyaluronic acid-curcumin conjugate suppresses the fibrotic functions of myofibroblasts from contractive joint by the PTGER2 demethylation. Regen Biomater 6(5):269-277. https://doi.org/10.1093/rb/ rbz016

108. Golchin A, Hosseinzadeh S, Ardeshirylajimi A (2018) The exosomes released from different cell types and their effects in wound healing. J Cell Biochem 119(7):5043-5052. https://doi.org/10.1002/jcb.26706

109. Dickinson LE, Gerecht S (2016) Engineered biopolymeric scaffolds for chronic wound healing. Front Physiol 7:341. https://doi.org/10.3389/fphys.2 016.00341

110. Mutlu G, Calamak S, Ulubayram K, Guven E (2018) Curcumin-loaded electrospun PHBV nanofibers as potential wound-dressing material. J Drug Deliv Sci Technol 43:185-193. https://doi.org/10.1016/j.jddst.2017.09.017

111. Leaper DJ (2006) Silver dressings: their role in wound management. Int Wound J 3(4):282-294. https://doi.org/10.1111/j.1742-481X.2006.00265.X

112. Rushton I (2007) Understanding the role of proteases and $\mathrm{pH}$ in wound healing. Nurs Stand 21(32):68-74. https://doi.org/10.7748/ns2007.04.21.32.68.c4499

113. Brem H, Tomic-Canic M (2007) Cellular and molecular basis of wound healing in diabetes. J Clin Invest 117(5):1219-1222. https://doi.org/10.1172/ JCl32169

114. Jones LM, Rubadue C, Brown NV, Khandelwal S, Coffey RA (2015) Evaluation of TCOM/HBOT practice guideline for the treatment of foot burns occurring in diabetic patients. Burns 41:536-541. https://doi.org/10.1016/j.burns.2014. 08.001

115. Bonvallet PP, Schultz MJ, Mitchell EH, Bain JL, Culpepper BK, Thomas SJ, Bellis SL (2015) Microporous dermal-mimetic electrospun scaffolds preseeded with fibroblasts promote tissue regeneration in full-thickness skin wounds. PLoS One 10(3):e0122359. https://doi.org/10.1371/journal.pone. 0122359

116. Ilomuanya MO, Okafor PS, Amajuoyi JN, Onyejekwe JC, Okubanjo OO, Adeosun SO, Silva BO (2020) Polylactic acid-based electrospun fiber and hyaluronic acid-valsartan hydrogel scaffold for chronic wound healing. Beni Suef Univ J Basic Appl Sci 9. https://doi.org/10.1186/s43088-020-00057-9

117. Ahangari N, Kargozar S, Ghayour-Mobarhan M, Baino F, Pasdar A, Sahebkar A, Ferns GAA, Kim H, Mozafari M (2019) Curcumin in tissue engineering: a traditional remedy for modern medicine. BioFactors 45(2):135-151. https:// doi.org/10.1002/biof.1474

118. Panahi Y, Fazlolahzadeh O, Atkin SL, Majeed M, Butler AE, Johnston TP, Sahebkar A (2019) Evidence of curcumin and curcumin analogue effects in skin diseases: a narrative review. J Cell Physiol 234(2):1165-1178. https://doi. org/10.1002/jcp.27096

119. Li AN, Li S, Zhang YJ, Xu XR, Chen YM, Bin LH (2014) Resources and biological activities of natural polyphenols. Nutrients 6(12):6020-6047. https://doi.org/10.3390/nu6126020

120. Jovanovic SV, Steenken S, Boone CW, Simic MG (1999) H-atom transfer is a preferred antioxidant mechanism of curcumin. J Am Chem Soc 121(41): 9677-9681. https://doi.org/10.1021/ja991446m

121. Barclay LRC, Vinqvist MR, Mukai K, Goto H, Hashimoto Y, Tokunaga A, Uno H (2000) On the antioxidant mechanism of curcumin: classical methods are needed to determine antioxidant mechanism and activity. Org Lett 2(18): 2841-2843. https://doi.org/10.1021/ol000173t

122. Akbik D, Ghadiri M, Chrzanowski W, Rohanizadeh R (2014) Curcumin as a wound healing agent. Life Sci 116(1):1-7. https://doi.org/10.1016/j.lfs.2014.08.016

123. Li X, Ye X, Qi J, Fan R, Gao X, Wu Y, Zhou L, Tong A, Guo G (2016) EGF and curcumin co-encapsulated nanoparticle/hydrogel system as potent skin regeneration agent. Int J Nanomedicine 11:3993-4009. https://doi.org/1 0.2147/IJN.S104350

124. Mohanty C, Das M, Sahoo SK (2012) Sustained wound healing activity of curcumin loaded oleic acid based polymeric bandage in a rat model. Mol Pharm 9(10):2801-2811. https://doi.org/10.1021/mp300075u 
125. Jordan AR, Racine RR, Hennig MJP, Lokeshwar VB (2015) The role of CD44 in disease pathophysiology and targeted treatment. Front Immunol 6:182. https://doi.org/10.3389/fimmu.2015.00182

126. Chou PY, Chen SH, Chen CH, Chen SH, Fong YT, Chen JP (2017) Thermoresponsive in-situ forming hydrogels as barriers to prevent post-operative peritendinous adhesion. Acta Biomater 63:85-95. https://doi.org/10.1016/j.a ctbio.2017.09.010

127. Schanté CE, Zuber G, Herlin C, Vandamme TF (2011) Chemical modifications of hyaluronic acid for the synthesis of derivatives for a broad range of biomedical applications. Carbohydr Polym 85(3):469-489. https://doi.org/1 0.1016/j.carbpol.2011.03.019

128. Heidari S, Mahdiani S, Hashemi M, Kalalinia F (2020) Recent advances in neurogenic and neuroprotective effects of curcumin through the induction of neural stem cells. Biotechnol Appl Biochem 67:bab.1891. https://doi.org/1 0.1002/bab.1891

129. Sikazwe D, Yendapally R, Ramsinghani S, Khan M (2017) Alzheimer's drug discovery maze: a snap view of the past decade's diverse pharmacological targets for the disorder. Mini Rev Med Chem 17(3):305-318. https://doi. org/10.2174/1389557516666160822152625

130. Burns A, lliffe S (2009) Alzheimer's disease. BMJ 338(feb05 1):467-471. https://doi.org/10.1136/bmj.b158

131. What are the signs of Alzheimer's disease? | National Institute on Aging. https://www.nia.nih.gov/health/what-are-signs-alzheimers-disease. Accessed 2 Dec 2020

132. Ashford JW (2015) Treatment of Alzheimer's disease: the legacy of the cholinergic hypothesis, neuroplasticity, and future directions. J Alzheimers Dis 47(1):149-156. https://doi.org/10.3233/JAD-150381

133. Hardy J, Selkoe DJ (2002) The amyloid hypothesis of Alzheimer's disease: progress and problems on the road to therapeutics. Science 297:353-356. https://doi.org/10.1126/science.1072994

134. Ono K, Hasegawa K, Naiki H, Yamada M (2004) Curcumin has potent antiamyloidogenic effects for Alzheimer's $\beta$-amyloid fibrils in vitro. J Neurosci Res 75(6):742-750. https://doi.org/10.1002/jnr.20025

135. Chan S, Kantham S, Rao VM, Palanivelu MK, Pham HL, Shaw PN, McGeary RP, Ross BP (2016) Metal chelation, radical scavenging and inhibition of A 42 fibrillation by food constituents in relation to Alzheimer's disease. Food Chem 199:14-24. https://doi.org/10.1016/j.foodchem.2015.11.118

\section{Publisher's Note}

Springer Nature remains neutral with regard to jurisdictional claims in published maps and institutional affiliations.

\section{Submit your manuscript to a SpringerOpen ${ }^{\circ}$ journal and benefit from:}

- Convenient online submission

- Rigorous peer review

- Open access: articles freely available online

- High visibility within the field

- Retaining the copyright to your article

Submit your next manuscript at $\boldsymbol{\nabla}$ springeropen.com 